\title{
Metal complexation by histidine-rich peptides confers protective roles against cadmium stress in Escherichia coli as revealed by proteomics analysis
}

\author{
Patcharee Isarankura-Na-Ayudhya ${ }^{1}$, Chadinee Thippakorn ${ }^{2}$, Supitcha Pannengpetch ${ }^{2}$, Sittiruk Roytrakul ${ }^{3}$, \\ Chartchalerm Isarankura-Na-Ayudhya ${ }^{\text {Corresp.. }}{ }^{4}$, Nipawan Bunmee ${ }^{1}$, Suchitra Sawangnual ${ }^{1}$, Virapong \\ Prachayasittikul ${ }^{4}$ \\ 1 Department of Medical Technology, Faculty of Allied Health Science, Thammasat University, Pathumthani, Thailand \\ 2 Center for Research and Innovation, Faculty of Medical Technology, Mahidol University, Bangkok, Thailand \\ ${ }^{3}$ Genome Institute, National Center for Genetic Engineering and Biotechnology, National Science and Technology Development Agency, Pathumthani, \\ Thailand \\ 4 Department of Clinical Microbiology and Applied Technology, Faculty of Medical Technology, Mahidol University, Bangkok, Thailand \\ Corresponding Author: Chartchalerm Isarankura-Na-Ayudhya \\ Email address: chartchalerm.isa@mahidol.ac.th
}

The underlying mechanism and cellular responses of bacteria against toxic cadmium ions is still not fully understood. Herein, Escherichia coli TG1 expressing hexahistidine-green fluorescent protein (His6GFP) and cells expressing polyhistidine-fused to the outer membrane protein A (His-OmpA) were applied as models to investigate roles of cytoplasmic metal complexation and metal chelation at the surface membrane, respectively, upon exposure to cadmium stress. Two-dimensional gel electrophoresis (2DE) and Two-Dimensional Difference in Gel Electrophoresis (2D-DIGE) in conjunction with mass spectrometry-based protein identification had successfully revealed the low level expression of antioxidative enzymes and stress-responsive proteins such as manganesesuperoxide dismutase (MnSOD; +1.65 fold), alkyl hydroperoxide reductase subunit C (AhpC; +1.03 fold) and DNA starvation/stationary phase protection protein (Dps; -1.02 fold) in cells expressing His6GFP in the presence of $0.2 \mathrm{mM}$ cadmium ions. By contrarily, cadmium exposure led to the up-regulation of MnSOD of up to +7.20 and +3.08 fold in TG1-carrying pUC19 control plasmid and TG1 expressing native GFP, respectively, for defensive purposes against $\mathrm{Cd}$-induced oxidative cell damage. Our findings strongly support the idea that complex formation between cadmium ions and His6GFP could prevent reactive oxygen species (ROS) caused by interaction between $\mathrm{Cd}^{2+}$ and electron transport chain. This coincided with the evidence that cells expressing His6GFP could maintain their growth pattern in a similar fashion as that of the control cells even in the presence of harmful cadmium. Interestingly, overexpression of either OmpA or His-OmpA in $E$. coli cells has also been proven to confer protection against cadmium toxicity as comparable to that observed in cells expressing His6GFP. Blockage of metal uptake as a 
consequence of anchored polyhistidine residues on surface membrane limited certain amount of cadmium ions in which some portion could pass through and exert their toxic effects to cells as observed by the increased expression of MnSOD of up to +9.91 and +3.31 fold in case of TG1 expressing only OmpA and His-OmpA, respectively. Plausible mechanisms of cellular responses and protein mapping in the presence of cadmium ions were discussed. Taken altogether, we propose that the intracellular complexation of cadmium ions by metal-binding regions provides more efficiency to cope with cadmium stress than the blockage of metal uptake at the surface membrane. Such findings provide insights into the molecular mechanism and cellular adaptation against cadmium toxicity in bacteria. 
1 Metal complexation by histidine-rich peptides confers protective roles against cadmium

4 Patcharee Isarankura-Na-Ayudhya ${ }^{1}$, Chadinee Thippakorn ${ }^{2}$, Supitcha Pannengpetch ${ }^{2}$, Sittiruk

5 Roytrakul $^{4}$, Chartchalerm Isarankura-Na-Ayudhya ${ }^{3 *}$, Nipawan Bunmee ${ }^{1}$, Suchitra Sawangnual ${ }^{1}$,

6 Virapong Prachayasittikul ${ }^{3}$

$8{ }^{1}$ Department of Medical Technology, Faculty of Allied Health Science, Thammasat University,

9 Pathumthani 12120, Thailand

$10{ }^{2}$ Center for Research and Innovation, Faculty of Medical Technology, Mahidol University,

11 Bangkok 10700, Thailand

$12{ }^{3}$ Department of Clinical Microbiology and Applied Technology, Faculty of Medical

13 Technology, Mahidol University, Bangkok 10700, Thailand

$14{ }^{4}$ Genome Institute, National Center for Genetic Engineering and Biotechnology, National

15 Science and Technology Development Agency, Pathumthani 12120, Thailand

18 *Corresponding author: Professor Chartchalerm Isarankura-Na-Ayudhya, Ph.D.

19 E-mail: chartchalerm.isa@mahidol.ac.th; Telephone: 662-441-4376; Fax: 662-441-4380 
23 The underlying mechanism and cellular responses of bacteria against toxic cadmium ions is still not fully understood. Herein, Escherichia coli TG1 expressing hexahistidine-green fluorescent protein (His6GFP) and cells expressing polyhistidine-fused to the outer membrane protein A (His-OmpA) were applied as models to investigate roles of cytoplasmic metal complexation and metal chelation at the surface membrane, respectively, upon exposure to cadmium stress. Twodimensional gel electrophoresis (2-DE) and Two-Dimensional Difference in Gel Electrophoresis (2D-DIGE) in conjunction with mass spectrometry-based protein identification had successfully revealed the low level expression of antioxidative enzymes and stress-responsive proteins such as manganese-superoxide dismutase (MnSOD; +1.65 fold), alkyl hydroperoxide reductase subunit $\mathrm{C}(\mathrm{AhpC} ;+1.03$ fold) and DNA starvation/stationary phase protection protein (Dps; 1.02 fold) in cells expressing His6GFP in the presence of $0.2 \mathrm{mM}$ cadmium ions. By contrarily, cadmium exposure led to the up-regulation of MnSOD of up to +7.20 and +3.08 fold in TG1carrying pUC19 control plasmid and TG1 expressing native GFP, respectively, for defensive purposes against $\mathrm{Cd}$-induced oxidative cell damage. Our findings strongly support the idea that complex formation between cadmium ions and His6GFP could prevent reactive oxygen species (ROS) caused by interaction between $\mathrm{Cd}^{2+}$ and electron transport chain. This coincided with the evidence that cells expressing His6GFP could maintain their growth pattern in a similar fashion as that of the control cells even in the presence of harmful cadmium. Interestingly, overexpression of either OmpA or His-OmpA in E. coli cells has also been proven to confer protection against cadmium toxicity as comparable to that observed in cells expressing His6GFP. Blockage of metal uptake as a consequence of anchored polyhistidine residues on surface membrane limited certain amount of cadmium ions in which some portion could pass through 
45 and exert their toxic effects to cells as observed by the increased expression of MnSOD of up to $46+9.91$ and +3.31 fold in case of TG1 expressing only OmpA and His-OmpA, respectively.

47 Plausible mechanisms of cellular responses and protein mapping in the presence of cadmium

48 ions were discussed. Taken altogether, we propose that the intracellular complexation of

49 cadmium ions by metal-binding regions provides more efficiency to cope with cadmium stress

50 than the blockage of metal uptake at the surface membrane. Such findings provide insights into

51 the molecular mechanism and cellular adaptation against cadmium toxicity in bacteria. 
54 Cadmium ion is considered to be one of the harmful heavy metals that exerts its toxicities to 55 all organisms including human, animals and microorganisms (Vallee \& Ulmer 1972). In

56 microbes, the most common toxicity includes mutagenic effect, growth inhibition, physiological

57 alterations and inhibition of enzymatic activities in metabolic pathway (Bischoff 1982). Most of

58 the microorganisms attempt to adapt themselves naturally from these metals by utilizing several

59 cellular responses, e.g. reduction of metal-uptake process, sequestration of metal ions by

60 biological macromolecules, transportation of metal ions out by efflux system, transformation of

61 toxic metals by reductase enzymes, and metal sorption by biofilm and siderophores (Giovanella

62 et al. 2017; Nies 1999). Among these, active efflux has been thought to be the primary

63 mechanism developed in prokaryotes to reduce intracellular cadmium ions. By contrarily,

64 intracellular complexation of the toxic cadmium ion by cadmium-binding components such as

65 metallothioneins and phytochelatins is mainly used in eukaryotes (Nies 1992).

66 In case of well-known bacteria e.g. Escherichia coli (E. coli), research findings during the

67 past 50 years stated the toxic effects of cadmium ions and significant cellular responses and 68 adaptation in various aspects as followings. (i) Cadmium toxicity: $\mathrm{Cd}^{2+}$ is readily taken up by $E$.

69 coli cells by means of an active transport system with a $K_{m}$ of approximately $2.1 \mu \mathrm{M}$ (Laddaga \&

70 Silver 1985). Exposure to cadmium ion results in long lag phase of cell proliferation, reduction

71 of cell survival and loss of their ability to form colony (Mitra 1984; Mitra \& Bernstein 1978;

72 Mitra et al. 1975). Explanations to those phenomena could be accounted as the breakage of

73 single-strand DNA, inhibition of metalloenzyme (i.e. alkaline phosphatase) and aggregation of

74 cytoplasmic materials (Mitra \& Bernstein 1978; Mitra et al. 1975). Other toxic effects including

75 disturbation of the cell division as a consequence of improper Z-ring formation, metabolic 
76 dysfunction, and imbalance of oxidative pressure leading to growth retardation were reported

77 (Hossain et al. 2012). Induction of oxidative damage by superoxide radical together with

78 inability to express protective enzymes and to replace damaged proteins by de novo protein

79 synthesis have currently been reported to be the main reason for growth stasis and cell death in

80 Cd poisoning(Thomas \& Benov 2018). (ii) Cellular responses and adaptation: To reduce the

81 toxic effects of cadmium ions, efflux system has not much been accepted as the primary defense

82 mechanism of E. coli. Several reports stated that E. coli protected themselves against harmful

83 cadmium mainly by synthesis of cytoplasmic cadmium-binding proteins to accumulate free $\mathrm{Cd}^{2+}$

84 intracellularly (Cohen et al. 1991; Khazaeli \& Mitra 1981; Mitra 1984). Such accumulation was

85 proposed to control internal environment and probably to resume normal metabolic function after

86 the long lag phase (Khazaeli \& Mitra 1981). Another group of protein, namely cadmium-induced

87 proteins (CDPs), was also produced as a stress-responsive protein during cadmium exposure

88 (Ferianc et al. 1998). Among the CDPs, YodA protein (a protein containing histidine-rich N-

89 terminal sequence; HGHHSH) has been extensively studied. It was found that the YodA protein

90 mainly localized in both cytoplasm and periplasm but was only tranlocated into a periplasmic

91 space during cadmium stress (Puskárová et al. 2002). It is believed that the role of YodA protein

92 might be to decrease the intracellular concentration of cadmium ions by its ability to bind heavy

93 metal (Stojnev et al. 2007). Moreover, the YodA protein is hypothesized to be part of a

94 cadmium-exporting transport protein due to its sequence similarity to the C-terminal domain of a

95 metal-binding receptor of a member of bacterial ATP-binding cassette transporters (David et al.

96 2003). In recent studies, the YodA has also been recognized as the ZinT, a metal-binding protein

97 involved in zinc homeostasis (Kershaw et al. 2007). Such involvement of histidine-rich peptide

98 in the reduction of cadmium toxicity as well as in cadmium translocation strongly supports a 
99 significant role of histidine residue in metal regulation in bacterial cells. Altogether, it seems that

100 E. coli naturally utilizes both of the intracellular complexation and metal transporting system to

101 cope with cadmium stress but the proportion of which is not well understood. Currently,

102 regulation of the CDPs together with the other general stress responses was subsequently studied

103 either at the transcriptional or translational levels by gene-array technology or two-dimensional

104 gel electrophoresis (Brocklehurst \& Morby 2000; Ferianc et al. 1998; Isarankura-Na-Ayudhya et

105 al. 2009; Lausova et al. 1999). Results revealed that some regulatory systems, e.g. OxyR, SoxRS,

$106 \mathrm{RpoH}, \mathrm{UspA}$, GrpE, RecA, and YodA, participated in the cadmium stress (Ferianc et al. 1998;

107 LaRossa et al. 1995; Lim et al. 2009; Puskárová et al. 2002; Shapiro \& Keasling 1996; Thomas

108 \& Benov 2018; Van Dyk et al. 1995). These inducible regulators can be classified in various

109 groups as general stress regulons (UspA, YodA), SOS regulons (RecA), oxidative stress regulons

110 (Oxy R, SoxRS), heat shock protein regulons (RpoH) and chaperones (GrpE) (Han \& Lee 2006).

111 It can be speculated that there will be some interconnection between these regulons in the

112 cadmium stress.

113 In parallel to those long-term studies, genetic engineering has extensively been applied to

114 construct metal-binding proteins in bacteria and other organisms. The most popular target

115 belongs to a group of cysteine-rich peptides known as metallothionein (MT) that is ubiquitously

116 found in various organisms. The expression of MTs had successfully conferred metal toleration

117 and/or intracellular metal accumulation against cadmium stress in many cases (He et al. 2014;

118 Hou et al. 1988; Kille et al. 1990; Romeyer et al. 1988). Even though, the thiol group of cysteine

119 residues acts as soft Lewis base that preferably binds to cadmium ions (served as soft Lewis

120 acid). However, the difficulty to control their reduced states limits their maximum binding

121 capability to cadmium ions (Mahnam et al. 2017). Moreover, the overexpression of proteins 
122 containing thiol-moiety is reported to alter the redox-regulating system and growth

123 characteristics of E. coli (Kondo et al. 2000). Therefore, histidine residue (another amino acid

124 known to coordinate with divalent ions) has widely been selected for cadmium binding and

125 bioremediation purposes (Nair \& Robinson 2001; Patel et al. 2010; Samuelson et al. 2000; Sousa

126 et al. 1996). The presence of histidine-rich peptides had conferred the engineered E. coli the

127 capability to accumulate higher amounts of cadmium ions ( $\sim 11$-fold $)$ than that of the control

128 (Sousa et al. 1996). Such findings explore the efficiency of applying metal-binding amino

129 acids/peptides as tools not only to seek for their potential usages in bioremediation but also to

130 study the molecular mechanism of metal toleration.

131 Herein, a proteomic profiling of E. coli TG1 upon exposure to sub-lethal dose of cadmium

132 ions has been analyzed by using Two-dimensional gel electrophoresis (2-DE) and Two-

133 Dimensional Difference in Gel Electrophoresis (2D-DIGE) in conjunction with mass

134 spectrometry-based protein identification. Engineered E. coli cells expressing metal-binding

135 regions on the outer membrane or cytoplasm have been utilized in order to test whether

136 controlling of metal transport across the membrane or intracellular metal complexation played

137 major roles in modulating cellular adaptations against toxic cadmium ions. Particularly, the

138 expression of green fluorescent protein carrying hexahistidine (His6GFP) or polyhistidine fused

139 to outer membrane protein A (His-OmpA) have been used as models to mimic metal-binding

140 regions located in the cytoplasm and on surface membrane, respectively. It has previously been

141 reported that the expression of chimeric His6GFP could modulate metal homeostasis and

142 mobility inside E. coli cells (Isarankura-Na-Ayudhya et al. 2005). The rationale behind the

143 expression of histidine-rich peptide in the cytoplasm is expected to chelate cadmium ions in

144 order to prevent the sequelae of cadmium-induced oxidative cell damage via reactive oxygen 
145 species. The expression of His-OmpA has also been found to provide high binding affinity for

146 metal ions at the surface of E. coli (Isarankura-Na-Ayudhya et al. 2005). The presence of

147 polyhistidine on the cell surface is expected to trap cadmium ions and limit certain amount of

148 cadmium to transport across the membrane.Then, the investigation of differentially-expressed

149 proteins between these engineered E. coli and control cells has been conducted as to gain a better

150 understanding on the alternative ways that bacteria acclimatize themselves in toxic environment

151 as compared to those observed in nature. 
Bacterial strain and plasmids

E. coli strain TG1 (supE, $h s d \Delta 5$, thi $\Delta$ (lac-proAB), F'[traD36 proAB + lac $\mathrm{I}^{\mathrm{q}}$ lacZ $\left.\Delta \mathrm{M} 15\right]$ was

used as host cell. To express cytoplasmic metal-binding motifs, a plasmid designated as

pHis6GFPuv (Isarankura-Na-Ayudhya et al. 2005) that encodes a chimeric green fluorescent

protein carrying hexahistidine was transformed and further expressed in host cells. Cells

harboring pUC19 and pGFPuv (Clontech Laboratories, USA) were used as controls. In parallel, a

plasmid namely pEVZn (Mejare et al. 1998) that codes for the outer membrane protein A-

161 polyhistidine fusion protein was expressed in order to generate cells expressing surface metal-

162 binding motifs. For comparison, cells harboring pEV208 (Mejare et al. 1998) was used to overexpress the outer membrane protein.

\section{Growth patterns of cells in the presence of sub-lethal dose of cadmium ions}

All of the aforementioned cells with the exception of $E$. coli host were grown in $5 \mathrm{ml}$ Luria-

Bertani (LB) broth (10 g/L tryptone, $5 \mathrm{~g} / \mathrm{L} \mathrm{NaCl}$ and $5 \mathrm{~g} / \mathrm{L}$ yeast extract, $\mathrm{pH} 7.2)$ that is supplemented with $100 \mathrm{mg} / \mathrm{L}$ ampicillin at $37^{\circ} \mathrm{C}, 150 \mathrm{rpm}$ for overnight. The cultivation of the

TG1 host was performed in a similar manner but without the addition of ampicillin. Then, $50 \mu 1$ of overnight cultures were transferred into $5 \mathrm{ml}$ broth and grown until $\mathrm{OD}_{600}$ reached 0.5 . Cells were adjusted to equal optical density at $0.05 \mathrm{in} 5 \mathrm{ml} \mathrm{LB}$ broth supplemented with $100 \mathrm{mg} / \mathrm{L}$ ampicillin. Dose response assay was performed by addition of cadmium chloride stock solution

173 to yield final concentrations of 0-1.0 mM.Cultures were further incubated at $37^{\circ} \mathrm{C}, 150 \mathrm{rpm}$ for

$17412 \mathrm{~h}$. The growth rate was determined by monitoring the absorbance at $600 \mathrm{~nm}$ by 
175 spectrophotometer. It is noteworthy that the sublethal dose of $0.2 \mathrm{mM}$ cadmium ions (exhibiting

$176 \sim 50 \%$ growth inhibition of TG1 host) was selected as an effective dose for further experiments.

177

178 Two-dimensional gel electrophoresis (2-DE) of crude protein extracts

179 Overnight cultures of cells in $5 \mathrm{ml} \mathrm{LB}$ or LB/Amp were adjusted to $\mathrm{OD}_{600}$ of 1.0. One

180 milliliter of cell suspension was inoculated into $50 \mathrm{ml} \mathrm{LB}$ or LB/Amp. Cells were grown at

$18137^{\circ} \mathrm{C}, 150 \mathrm{rpm}$ for $3 \mathrm{~h}$ prior to addition of $\mathrm{CdCl}_{2}$ to yield the final concentration of $0.2 \mathrm{mM}$.

182 Cultivation was continued at $37^{\circ} \mathrm{C}, 150 \mathrm{rpm}$ for $15 \mathrm{~h}$. Cells were collected by centrifugation at

$1834^{\circ} \mathrm{C}, 6,000 \mathrm{rpm}$ for $10 \mathrm{~min}$. Crude protein extracts were prepared as previously described

184 (Isarankura-Na-Ayudhya et al. 2010). The protein concentration was measured by Bradford's

185 method (Bio-Rad protein assay, Bio-Rad Laboratory, CA). These protein extracts were subjected

186 to two-dimensional gel electrophoresis as follows. Three hundred micrograms of protein extract

187 was mixed thoroughly with $250 \mu$ of rehydration buffer ( $8 \mathrm{M}$ urea, $4 \%$ CHAPS, $2 \mathrm{mM}$ TBP,

$1880.001 \%$ bromphenol blue, $2.8 \mathrm{mg} / \mathrm{ml}$ dithiothreitol and $12 \mu \mathrm{l} / \mathrm{ml}$ destreak) containing 1\% 3-10

189 IPG buffer and stored at room temperature for $10 \mathrm{~min}$. Removal of insoluble material was further

190 performed by spinning at $13,000 \mathrm{rpm}$ for $10 \mathrm{~min}$ at $20^{\circ} \mathrm{C}$. The $13-\mathrm{cm}$ IPG strips (pH range of 3-

191 10) were placed in the IPGphor strip holder gel-side-down in rehydration solution containing

192 sample proteins. These strips were then covered with mineral oil. Samples were run through

193 steps of strip rehydration $(30 \mathrm{~V}, 12 \mathrm{~h})$ and isoelectric focusing $(500 \mathrm{~V}$ for $1 \mathrm{~h}, 1,000 \mathrm{~V}$ for $1 \mathrm{~h}$,

194 and $8,000 \mathrm{~V}$ to reach $16,000 \mathrm{~V} \cdot \mathrm{h})$. The maximum current was maintained at $50 \mathrm{~mA}$ per strip.

195 Once complete, the strip was equilibrated for two times (15 min each) in equilibration buffer (50

$196 \mathrm{mM}$ Tris $\mathrm{pH}$ 8.8, $6 \mathrm{M}$ urea, 30\% glycerol, 2\% SDS, 0.03\% bromphenol blue) supplemented with

$19765 \mathrm{mM}$ DTT and $135 \mathrm{mM}$ iodoacetamide. The separation of protein in the second dimension was 
198 performed using Hoefer ${ }^{\mathrm{TM}}$ DALT on $12.5 \%$ SDS-polyacrylamide gels. Proteins were separated

199 under applied voltage of $250 \mathrm{~V}, 10 \mathrm{~mA}$ per strip at $20^{\circ} \mathrm{C}$ for $30 \mathrm{~min}$ following by $250 \mathrm{~V}, 20 \mathrm{~mA}$

200 per strip at $20^{\circ} \mathrm{C}$ for $2.5 \mathrm{~h}$ until the bromphenol blue dye front reached $0.5 \mathrm{~cm}$ from the bottom of

201 the gel. Gels were further stained with colloidal Coomassie brilliant blue G for overnight. Excess

202 dye was removed by rinsing several times with deionized distilled water. Gels were scanned with

203 the Canoscan LiDE20 scanner (Canon, USA). Intensity of protein spots was analyzed by the 204 ImageJ software tool.

\section{Protein Labeling and Two-Dimensional Difference in Gel Electrophoresis (2D-DIGE)}

Healthcare, USA). Then, protein pellets were dissolved in a buffer containing $30 \mathrm{mM}$ Tris- $\mathrm{HCl}$,

$7 \mathrm{M}$ urea, $2 \mathrm{M}$ thiourea, 4\% (w/v) CHAPS, $\mathrm{pH}$ 8.5. Proteins were subsequently labeled with randomly labeled with 400 pmol Cy3 or Cy5, and the internal standard was labeled with Cy2 for

$21430 \mathrm{~min}$ on ice. Samples were then rehydrated into $18 \mathrm{~cm}$ IPG strips (pH 3-10 NL) (GE

215 Healthcare, UK) overnight in rehydration buffer (8 M urea, 4\% CHAPS, $13 \mathrm{mM}$ dithiothreitol, and 1\% IPG buffer 3-10 NL). Isoelectric focusing was carried out using an IPGphor III apparatus

217 (GE Healthcare, UK) according to the following procedures: $500 \mathrm{~V}$ for $500 \mathrm{~V} \cdot \mathrm{h}, 1,000 \mathrm{~V}$ for 800

$218 \mathrm{~V} \cdot \mathrm{h}$, and $10,000 \mathrm{~V}$ to reach $36,000 \mathrm{~V} \cdot \mathrm{h}$. Strips were further equilibrated for $15 \mathrm{~min}$ in

219 equilibration buffer (75 mM Tris- $\mathrm{HCl} \mathrm{pH} 8.8,6 \mathrm{M}$ urea, 30\% glycerol, 2\% SDS, 0.002\%

220 bromphenol blue) containing 1\% DTT and then for 15 min with $2.5 \%$ iodoacetamide. 
221 Equilibrated IPG strips were transferred onto 12.5\% SDS-polyacrylamide gels that had been pre-

222 casted in low fluorescence glass plates. The second dimension separation was then carried out at

$22310 \mathrm{~W} /$ gel using Ettan Dalt six electrophoresis system (GE Healthcare, UK).

224

225

226

227

228

229

230

231

232

233

234

235

236

237

238

239

240

241

242

243

Gel Image Analysis. 2D-DIGE gels were visualized using a Typhoon TRIO fluorescence scanner (GE Healthcare, UK) with excitation/emission at 532/580 nm (Cy3), 633/670 nm (Cy5) and 488/520 nm (Cy2). Scanning resolution used was $100 \mu \mathrm{m}$ with photomultiplier of $550 \mathrm{~V}$. Gel image and statistical analyses were performed using the DeCyder ${ }^{\mathrm{TM}}$ 2D Differential Analysis Software (DeCyder 2D version 7.2) by differential in-gel analysis (DIA) and biological variation analysis (BVA). Gels were subjected to silver staining for spot visualization and picking.

\section{Peptide mass fingerprinting (PMF) analysis}

Peptide mass fingerprinting (PMF) analysis of the protein separated by 2-DE was performed as previously described (Isarankura-Na-Ayudhya et al. 2010). The experiment was initiated by cutting spots of protein from gels and these spots were further transferred to 96-well microtitre plate and then soaked in 50\% methanol and 5\% acetic acid for overnight. In-gel digestion of protein was performed by the addition of sequencing grade of modified trypsin (Promega, UK). Digested peptide fragments were extracted from gel segments on a Spot Handling Workstation (GE Healthcare, USA) using preset protocols from the manufacturer. Protein identification was further carried out using MALDI-TOF mass spectrometer (Model ReflexIV, Bruker Daltonics, FRG) based on peptide fingerprint map. The tryptic digested peptide was mixed with a solution of $10 \mathrm{mg} / \mathrm{ml} \alpha$-cyano-4-hydroxycinnamic acid (LaserBio Labs, France) in 66\% acetonitrile and $0.1 \%$ trifluoroacetic acid (TFA) and further spotted onto a 96-well target plate. The acquisition 
244 of mass spectra was conducted in the positive ion reflector delayed extraction mode using

245 approximately 200 laser shots. Creation of peak lists was performed using the XMASS software

246 (Bruker Daltonics, FRG). These peaks were then queried using the MASCOT search engine

247 (MatrixScience, http://www.matrixscience.com/) for protein identification. The reference

248 database used in this study was NCBInr 20130802 (31350673 sequences; 10834990394

249 residues). The searching criteria were as follows: complete carbamidomethylation of cysteine

250 and partial methionine oxidation; an initial mass tolerance of $\pm 1.2 \mathrm{Da}$; the number of missed

251 cleavage sites of up to 1 . The accuracy of the experimental to theoretical $p \mathrm{I}$ as well as the

252 molecular weight of proteins was carefully taken into consideration.

253

254 Protein network analysis

255 Identified proteins were queried using the STRING software version 9.05 (http://string-

$256 \mathrm{db}$. org/) in order to create functional protein association networks. This database weights and

257 integrates direct (physical) and indirect (functional) associations from various sources, e.g.

258 genetic context, high-throughput experiments, co-expression and previous knowledge.

259

260 Statistical analysis

261 For the 2D-DIGE gel analysis, only spots with changes having an abundance ratio of 1.5

262 fold and $P$ values $<0.05$ (Student's $t$-test) were marked and selected for further protein

263 identification. For the PMF analysis, search result score greater than 71 was considered to be of

264 significant difference $(p<0.05)$. 


\section{RESULTS}

267

268

269

270

271

272

273

274

275

276

277

278

279

280

281

282

283

284

285

286

287

Expression of green fluorescent protein of $E$. coli expressing cytoplasmic histidine-rich protein (chimeric His6GFP)

E. coli TG1 was applied as a host for the transformation of pUC19 (control plasmid), pGFPuv and pHis6GFP. Expression of the green fluorescent protein was confirmed by observing the bright greenish fluorescence of colonies of $E$. coli expressing native GFP or His6GFP under illumination with UV light (Figs. 1C and D). Meanwhile, no fluorescence was detected for TG1 host and TG1 carrying pUC19 (Figs. 1A and B).

\section{Effect of cadmium stress on $E$. coli expressing cytoplasmic histidine-rich protein (chimeric}

\section{His6GFP)}

In the absence of cadmium ions, it seems that the TG1 carrying a control plasmid (Fig. 2A) growed up in the LB broth faster than the others. A long lag phase ( $\sim 3.5-4$ hours) could be detected in the cells expressing native GFP (Fig. 2B). The growth pattern of cells expressing His6GFP (Fig. 2C) resembled those in between the TG1 carrying pUC19 (Fig. 2A) and the native GFP-expressing cells (Fig. 2B).

In the presence of effective dose of cadmium, a growth arrest could be observed in cells expressing native GFP (Fig. 2B). However, this suppressing effect was more pronounced in cells carrying pUC19 (Fig. 2A). Interestingly, cells expressing the hexahistidine-GFP fusion protein displayed similar growth rates in the presence and absence of cadmium ions (Fig. 2C).

Proteomics profiling of $E$. coli expressing cytoplasmic histidine-rich protein 
Experimentation was initiated via the preparation of a reference map of the E. coli host

289

290

291

292

293

294

295

296

297

298

299

300

301

302

303

304

305

306

307

308

309

310

proteome (Fig. 3). Approximately 200-250 spots of protein could be detected using a 13-cm IPG

strip with $\mathrm{pH}$ range of 3-10. Some of these spots were picked up for further identification via peptide mass fingerprinting as shown in Table 1. Most of the identified proteins pertained to energy metabolism, chaperones, heat shock proteins or stress proteins, transporters, protein synthesis machinery, and outer membrane protein.

Further experiments were conducted to address the functional roles of cytoplasmic histidinerich protein (His6GFP) on cellular adaptation against toxic cadmium ions. Therefore, protein expression profiles of $E$. coli expressing His6GFP grown in the absence or presence of $0.2 \mathrm{mM}$ $\mathrm{CdCl}_{2}$ (Fig. 4C) were compared with cells harboring pUC19 and cells expressing native GFP (as represented in Figs. 4A-B, respectively). Effects of cadmium ions on the expression of various proteins were scrutinized as follows. Aconitase, an enzyme implicated in the Tricarboxylic acid (TCA) cycle, was down-regulated and disappeared in cells expressing His6GFP. Translation elongation factor-Ts was up-regulated in all cases (at 2.12, 1.84 and 1.35 fold for TG1/pUC19, TG1/GFP and TG1/His6GFP, respectively) (Table 2). Glycerol kinase, an enzyme involved in glycerol uptake and lipolysis, was up-regulated in cells expressing His6GFP (+1.92 fold) and native GFP (+1.73 fold). Oligopeptide-binding protein was down-regulated at -1.65 and -1.34 fold for control cells and cells expressing His6GFP while up-regulation was found in the case of GFP (+1.37 fold). The $\mathrm{H}^{+}$-transporting ATPase was up-regulated at 2.69 and 1.30 fold in case of control cells and cells expressing His6GFP, respectively. More importantly, the presence of cytoplasmic histidine residue due to the expression of His6GFP was found to play imperative roles in stress defense mechanisms. Manganese-superoxide dismutase (MnSOD), an oxidative scavenging enzyme, was found to be down-regulated in cells expressing His6GFP (-1.65 fold). 
311 Alkyl hydroperoxide reductase, a thiol-specific antioxidant protein, was up-regulated in the case

312 of native GFP-expressing cells $(+1.71$ fold). This is in contrast to those observed in the case of

313 His6GFP (-1.10 fold). For membrane proteins, our results revealed the down-regulation of

314 OmpC precursor (-1.15, -1.31 and -1.56 fold) and OmpF (-1.18 fold and absence) in all cases in

315 response to cadmium ions.

316

317 Functional roles of histidine residue fused with outer membrane protein in $E$. coli

318 It has previously been proven that the presence of polyhistidine on the surface membrane of

319 such engineered $E$. coli provided high binding affinity to zinc ions of up to 60-fold (Isarankura-

320 Na-Ayudhya et al. 2005). Therefore, these cells were applied in the current study in order to

321 reduce the cell permeability of cadmium ions. Fig. 5 demonstrates the growth patterns of

$322 \mathrm{TG} 1 / \mathrm{pEV} 208$ and TG1/pEVZn in the presence and absence of cadmium ions. Our results

323 revealed that the overexpression of the outer membrane protein of cells carrying plasmid

324 pEV208 could protect the cell growth from the hazardous effect of cadmium ions. More

325 importantly, the expression of polyhistidine-OmpA of cells harboring $\mathrm{pEVZn}$ could mediate a

326 little bit higher degree of cell division than that of cells expressing the OmpA alone. Results

327 from proteomics analysis revealed that the enzyme glyceraldehyde-3-phosphate dehydrogenase

328 form 1 was up-regulated in cells expressing OmpA (+2.69 fold) while the disapperance of this

329 enzyme was observed in the case of cells expressing His-OmpA (Fig. 6 and Table 2). A diverse

330 phenomenon was detected on the regulation of glyceraldehyde-3-phosphate dehydrogenase form

3312 at -2.29 and +1.63 fold for TG1/OmpA and TG1/His-OmpA, respectively. Furthermore, $\mathrm{H}^{+}-$

332 transporting ATPase was down-regulated in the case of the control (-2.64 fold) while no change

333 was found in cells expressing His-OmpA. In addition, cadmium ions stimulated expression of 
334 MnSOD in cells expressing His-OmpA ( +2.08 fold). It is noteworthy that increased amount of

335 the OmpC precursor was observed in cells expressing His-OmpA ( +2.11 fold $)$ as well as in cells

336 expressing OmpA alone ( +1.32 fold). Such finding is in contrast to those observed in the case of

337 cells expressing His6GFP and others as abovementioned.

338

339 Comparison of cadmium-induced protein alterations in engineered E. coli expressing

340 cytoplasmic polyhistidine and polyhistidine-anchored surface membrane

341 Differentially expressed proteins of engineered E. coli upon exposure to cadmium ions were

342 quantitatively identified as summarized in Table 2 . For enzymes implicated in energy

343 metabolism, glyceraldehyde-3-phosphate dehydrogenase form 1 was not detected in all cases

344 except cells expressing OmpA. The up-regulation of glyceraldehyde-3-phosphate dehydrogenase

345 form 2 was found in TG1 carrying pUC19, cells expressing native GFP and cells expressing His-

346 OmpA at 1.75, 1.65 and 1.63 fold, respectively. Aconitase was down-regulated in most cases. In

347 the meanwhile, the up-regulation of glycerol kinase was observed in the range of 1.3-1.9 fold in

348 all cases except for the control. For the protein synthesis machinery, all cell types (with the

349 exception of TG1 expressing OmpA) displayed approximately 1.3-2.1 fold increases. For

350 transporters, oligopeptide-binding protein was decreased $\sim 1.3-1.6$ fold only in the case of cells

351 expressing His6GFP and control cells. Increased amounts of amino acid ABC transporter

352 substrate-binding protein of 1.2-1.3 fold were found in TG1 expressing native GFP, His6GFP

353 and His-OmpA while no change was observed in control cells. In regards to the $\mathrm{H}^{+}$-transporting

354 ATPase, overexpressing of up to 2.7 fold was found in control cells. Up-regulation of

355 approximately 1.9 fold of ATP synthase F1 (membrane-bound ATP synthase) was notified in

356 cells expressing OmpA. For the stress defense mechanism, MnSOD is detected to be the most 
357 important antioxidative enzyme responsible for the toxic cadmium. Most cells enhanced the

358 production of MnSOD in the range of 1.29-2.20 fold. Importantly, down-regulation of MnSOD

359 ( $\sim 1.65$ fold) was found only in cells expressing cytoplasmic polyhistidine. It should be noted that

360 the up-regulation of $\mathrm{AphC}$ of up to 1.71 and 1.52 was found in TG1 expressing native GFP and

361 cells expressing only outer membrane protein. For the ribosomal protein L9, up-regulation in the

362 range of 1.3-2.1 fold was found in all cases with the exception of TG1 expressing His6GFP.

363 Moreover, an increased expression of the OmpC precursor of approximately 1.3-2.1 fold as

364 detected in cells expressing OmpA and His-OmpA. The disappearance of OmpF was observed in

365 TG1 expressing native GFP, His6GFP and His-OmpA.

366

367 Confirmation of cadmium-induced protein alterations using Two-Dimensional Difference

368

369

370

371

372

373

374

375

376

377

378

379

\section{in Gel Electrophoresis (2D-DIGE)}

To further confirm the protective roles of metal complexation by histidine-rich peptides against cadmium stress, quantitative proteomic investigation using 2D-DIGE was employed as to provide high sensitivity and high discrimination power on protein expression. As shown in Fig. $7 \mathrm{~A}$, three different samples were individually labeled with three fluorescent dyes (Cy2, Cy3 and Cy5) and co-separated in one gel, which mediates spot matching and quantitation in a simpler and more accurate manner. An internal standard, as derived from a mixture of all samples pooled together and labeled with $\mathrm{Cy} 2$, was created to facilitate the normalization of each spot among all gels. This provides a reliable and reproducible detection by minimizing gel-to-gel variation and increasing experimental efficiency (Westermeier \& Scheibe 2008). Up- or down-regulation of proteins was compared via the detection of fluorescence intensities of Cy3 and Cy5 simultaneously at different wavelengths. Different expression of three key proteins (MnSOD, 
380 AhpC and Dps) involved in the stress defense mechanism was selected for further investigation

381 (shown in Fig. 7B). Intracellular complexation of cadmium ions by His6GFP rendered cells to

382 express minute amount of MnSOD ( +1.65 fold) as compared to those of TG1 carrying pUC19

383 (+7.20 fold) and cells expressing native GFP (+3.08 fold). Similar observation was found with

384 regards to the compensation of MnSOD expression by the His-OmpA ( +3.31 fold) as compared

385 to cells expressing only OmpA ( +9.91 fold). The same phenomenon on the expression of AhpC

386 in cells expressing native GFP and cells expressing OmpA was observed (Fig. 7B and Table 2).

387 The high discriminative power of DIGE could quantify the up-regulation of Dps protein of up to

388 4.62, 1.82 and 3 fold in TG1 expressing native GFP, OmpA and His-OmpA, respectively.

389 Moreover, the quantification of aconitase expression was obtained in a tangible manner. Down-

390 regulation of aconitase of approximately 2.60 fold was detected in the case of TG1 expressing

391 His-OmpA upon exposure to cadmium ions. Cadmium ions also induced the expression of ClpB

392 of approximately 2.38 fold in TG1 expressing only OmpA. On the contrary, down-regulation of

$393 \mathrm{ClpB}$ of up to 2.03 fold was observed when cells expressed polyhistidine on their surface

394 membrane.

395

396 Interconnection between proteins implicated in cadmium stress

397 Analysis using the STRING software provided insights on the biological inference of

398 proteins implicated in cadmium stress. As shown in Fig. 8, most of the important proteins as

399 identified by 2-DE (Figs. 4, 6, 7 and Table 2) were mapped onto the protein network. MnSOD

400 encoded by the sodA gene is known to be regulated by the SoxRS regulon (Fig. 9). Even though,

401 alkyl hydroperoxide reductase (coded by AhpC gene) is under the control of the OxyR regulon,

402 however, these two enzymes have some cross-functional roles and have also the same connection 
403 point as mediated by the trxA gene (coding for thioredoxin). In addition, these enzymes also

404 function together with the F0F1 ATP synthase (an enzyme that regulates proton transportation

405 across the membrane and ATP synthesis/hydrolysis) linked via the trxA gene. MnSOD was also

406 found to share connectivity with aconitase enzyme (coded by AcnA and AcnB). Particularly,

407 aconitases serve as protective buffers against oxidative stress. AcnA enhances the stability of the

408 sodA transcript whereas AcnB lowers its stability (Han \& Lee 2006). The OxyR also plays an

409 important role on the regulation of DNA starvation/stationary phase protection protein (Dps).

410 The Dps unspecifically binds and protects DNA from oxidative damage mediated by hydrogen

411 peroxide (Han \& Lee 2006). Moreover, ClpB, which is known as a stress-induced multi-

412 chaperone system, was also found to possess linkages with these proteins and enzymes.

413 Interconnections between these proteins/enzymes provide new knowledge on the cellular

414 responses of bacteria in the presence of cadmium stress. 
Herein, alterations of protein expression profiles of $E$. coli as consequences of cadmium stress have successfully been investigated using 2-DE and 2D-DIGE in conjunction with mass

419 spectrometry-based protein identification. Differentially expressed proteins of TG1 expressing metal-binding regions in the cytoplasm and on the surface membrane provided insights into the underlying mechanisms of cellular adaptation against deleterious effects of cadmium ions (Fig. 9). In normal condition, $\mathrm{Cd}^{2+}$ is taken up by $E$. coli cells by an active transport system, in particular $\mathrm{Mn}^{2+}$ uptake system (Laddaga \& Silver 1985). Inside the cells, $\mathrm{Cd}^{2+}$ induces cell damage by generation of reactive oxygen species (ROS) through the electron transport chain (Pacheco et al. 2008; Thomas \& Benov 2018). The presence of superoxide radical $\left(\mathrm{O}_{2}^{2^{-}}\right)$ subsequently triggers the SoxRS regulon and results in the increased expression of antioxidative enzymes, mainly superoxide dismutase to protect the cells from cadmium stress (Geslin et al. 2001). In addition, the ROS also induces the OxyR and PerR regulons, which control the expression of catalase, peroxidases, alkyl hydroperoxide reductase enzymes. Toxic cadmium also stimulates the synthesis of cadmium-induced proteins (CDPs) such as DnaK, ClpB, RecA,

431 UspA to form the cadmium stress stimulon (Ferianc et al. 1998; Han \& Lee 2006).

432 This study proposes a detailed explanation on the adaptive mechanisms of the E. coli host in 433 response to toxic cadmium ions. From our findings, it can be suggested that cadmium afforded 434 the growth arrest of control cells (TG1 harboring pUC19) (Fig. 2A). In order to survive, E. coli 435 cells adapted themselves in several ways as follows:

436 i) Up-regulation of $\mathrm{H}^{+}$-transporting ATPase and ATP synthase $\mathrm{F} 1$ for controlling proton or 437 ions translocation as well as for ATP production. 
ii) Reduction of OmpA form 1 together with minor changes of the OmpC precursor and OmpF were detected since these outer membrane proteins were reported to participate in the homeostasis of divalent metal ions $\left(\mathrm{Cd}^{2+}, \mathrm{Zn}^{2+}\right.$ and $\left.\mathrm{Cu}^{2+}\right)($ Egler et al. 2005; Faber et al. 1993).

iii) Down-regulation of oligopeptide-binding protein might also be potentiated in order to reduce the uptake of cadmium ions into cells. It is known that the oligopeptide-binding protein is a component of the oligopeptide permease and the binding protein-dependent transport system (Han \& Lee 2006). In E. coli, the oligopeptide-binding protein (coded by the OppA gene) mainly functions as a mediator for the recycling of cell wall peptides (Wu \& Mandrand-Berthelot 1995). The protein displays quite a broad range of substrate specificity in which it can transport any peptide of a given length with a wide variety of amino acid composition. In some circumstances, the expression of oligopeptide-binding protein in E. coli also increased the uptake of aminoglycoside antibiotics (Acosta et al. 2005). Deletion of the OppA gene resulted in a decreased sensitivity against the aminoglycoside (Kashiwagi et al. 1992). Moreover, it cannot be excluded that the decreased amount of the oligopeptide-binding protein might be a result of oxidative stress. Since it has been reported to be one of the major oxidatively-damaged protein targets of $E$. coli in the presence of oxidative stress and iron overload (Tamarit et al. 1998).

iv) Once cadmium ions crossed the membranes, aconitase B was found to be markedly decreased and damaged due to its unusual FeS cluster (Helbig et al. 2008). Cadmium ions could also trigger the SoxRS regulon and consequently leads to the increased expression of MnSOD (+7.20 fold), which is involved as the primary stress defense 
mechanism. Our finding was in good agreement with other studies at the transcriptional and translational levels. It has previously been reported that the adapted strain of TG1, which could tolerate cadmium ions, exhibited different transcriptional profiles from the sensitive strain (Brocklehurst \& Morby 2000). The intracellular generation of superoxide radical by cadmium (Thomas \& Benov 2018), nickel and cobalt exerted toxic effects toward E. coli in which the participation of sod genes was regulated for the protection against metal stress (Geslin et al. 2001). Increased production of the SOD enzyme was found in the E. coli strain BL21 and P4 in the presence of cadmium (Khan et al. 2017; Shen et al. 2012).

v) In parallel, proteins involved in energy metabolism, e.g. glyceraldehyde-3-phosphate dehydrogenase and glycerol kinase, were down-regulated in order to reduce the energy consumption as required for cell survival. Therefore, the reduction of the oligopeptidebinding protein (mentioned in iii) and amino acid ABC transporter substrate-binding protein was observed for regulating the transportation of amino acid and other carbon sources during energy crisis (Isarankura-Na-Ayudhya et al. 2009).

To further confirm the aforementioned mechanisms, GFP harboring hexahistidine

479 On the contrary, the up-regulation of both antioxidant enzymes $(+3.08$ and +1.66 fold $)$ was found 480 in cells expressing only native GFP (Fig. 7B). Our findings indicated that the effective 481 complexation of cadmium ions by histidine residue provided protective roles against toxic 482 metals, possibly by inhibition of ROS production. It has been detected that the presence of 483 His6GFP rendered the cells to accumulate cadmium ions intracellularly up to $8.00 \pm 0.08$ 
484 nmole $/ 8 \times 10^{8}$ cells or $\sim 1.5$ fold higher than those of cells expressing native GFP $(5.35 \pm 0.45$

$485 \mathrm{nmole} / 8 \times 10^{8}$ cells $)$ and TG1 host $\left(5.34 \pm 0.7 \mathrm{nmole} / 8 \times 10^{8}\right.$ cells $)$. Such protection coincided with

486 the recovery of growth characteristics of His6GFP-expressing cells in the presence of cadmium

487 (Fig. 2C). However, it should be noted that the overexpression of native GFP somewhat

488 protected the E. coli cells from toxic cadmium (Fig. 2B). Plausible explanations might be

489 attributable to i) the quenching ability and SOD-like activity of the native GFP to detoxify the

490 superoxide radical (Bou-Abdallah et al. 2006) and ii) the increased transcription (Helbig et al.

491 2008) and translation of alkyl hydroperoxide reductase (AhpC) (Table 2 and Fig. 7B) under the

492 activation of OxyR. This enzyme belongs to a large family of thiol-specific antioxidant proteins

493 found in both prokaryotes and eukaryotes. It is known to detoxify not only peroxides but also

494 reactive oxygen-, nitrogen- and sulfur-species. Cloning of this enzyme from Anabaena spp. in E.

495 coli rendered cells to be more resistant against $\mathrm{CdCl}_{2}$ of up to $4 \mathrm{mM}$ (Mishra et al. 2009). In

496 other organisms, increased levels of alkyl hydroperoxide reductase protected the plant

497 pathogenic bacterium namely Xanthomonas campestris from peroxides and cadmium stress

498 (Banjerdkij et al. 2005). Mutant cells of Helicobacter pylori defective in AhpC were more

499 sensitive to oxidative stress conditions (Wang et al. 2005). In Saccharomyces cerevisiae,

500 disruption of the AHP1 gene rendered cells to be more susceptible to several kinds of metal ions

501 (Nguyen-nhu \& Knoops 2002).

502 Next, the blockage of metal uptake as a consequence of anchored polyhistidine residues on

503 surface membrane has also been proven to confer protection against cadmium toxicity in E. coli

504 (Fig. 5). Such protective effect is comparable to that observed in cells expressing His6GFP (Fig.

$5052 \mathrm{C}$ ). Results from proteomics analysis revealed differences of protein expression profiles among

506 these two cases as follows. Up-regulation of MnSOD, glyceraldehyde-3-phosphate 
507 dehydrogenase form 2, ribosomal protein L9 and OmpC precursor was found in cells expressing

508 His-OmpA. Importantly, down-regulation and no increased expression of ATP synthase F1 and

$509 \mathrm{H}^{+}$-transporting ATPase were observed. This infers that the binding of cadmium ions was

510 effectively potentiated at the surface membrane in which the regulation of ions-transporting

511 system was not induced. However, a minute amount of cadmium ions could pass through the

512 membrane portion and exert their toxic effects to cells as observed by the increased expression of

513 MnSOD. Moreover, expression of the OmpC precursor (membrane protein porin) proportionally

514 corresponded with information from transcriptional profiles of Cd-resistant strain of $E$. coli

515 (Brocklehurst \& Morby 2000). Meanwhile, a mutant strain lacking the $\mathrm{OmpC}$ gene was proven

516 to be sensitive to cadmium ions (Egler et al. 2005). In another case, the expression of OmpA

517 alone could also protect E. coli cells from cadmium-induced growth arrest (Fig. 5). However, the

518 induction of antioxidative scavenging enzyme consisting of AhpC and ATP synthase F1 was still

519 required (Table 2 and Fig. 7B). These results were in contrast to those observed in cells

520 expressing His6GFP (Table 2 and Fig. 7B). Therefore, all findings lend support to the notion that

521 metal complexation by cytoplasmic metal-binding protein afforded more efficiency to cope with

522 cadmium stress than the metal-binding affinity at the surface membrane (Fig. 9).

523

\section{Conclusion}

525 This study explores the underlying mechanism and cellular responses of bacteria against toxic 526 cadmium ions. Particularly, E. coli TG1 expressing His6GFP and His-OmpA were used as 527 models for studying the roles of cytoplasmic metal complexation and metal chelation at the 528 surface membrane, respectively, upon exposure to cadmium stress (Fig. 9). Results from 2-DE 529 and 2D-DIGE together with mass spectrometry-based protein identification had revealed that the 
530 complexation of cadmium ions by His6GFP helped to reduce toxicity of cadmium-induced

531 oxidative cell damage via initial inhibition of ROS production. Supportive evidences could be

532 accounted mainly by the low expression level of antioxidative enzymes and stress responsive

533 proteins under the regulations of SoxRS and OxyR as compared to those derived from the effect

534 of His-OmpA. Thus, it can be rationalized that the complex formation between cadmium ions

535 and histidine-rich peptides/proteins provides more efficiency to cope with cadmium stress than

536 the blockage of metal uptake at the surface membrane. Such findings shed light on the molecular

537 mechanism and cellular adaptation of bacteria against cadmium toxicity.

538

539 Acknowledgments

540 Nipawan Bunmee and Suchitra Sawangnual are undergraduate students under the supervision of 541 Patcharee Isarankura-Na-Ayudhya. 
545

546

547

548

549

550

551

552

553

554

555

556

557

558

559

560

561

562

563

564

565

566

567

568

569

570

571

572

573

574

575

576

577

578

579

580

581

582

583

584

585

586
Acosta MB, Ferreira RC, Ferreira LC, Costa SO. 2005. Intracellular polyamine pools, oligopeptide-binding protein A expression, and resistance to aminoglycosides in Escherichia coli. Mem Inst Oswaldo Cruz 100:789-793

Banjerdkij P, Vattanaviboon P, Mongkolsuk S. 2005. Exposure to cadmium elevates expression of genes in the OxyR and OhrR regulons and induces cross-resistance to peroxide killing treatment in Xanthomonas campestris. Applied and environmental microbiology 71:18431849

Bischoff B. 1982. Effects of cadmium on microorganisms. Ecotoxicology and Environmental Safety 6:157-165

Bou-Abdallah F, Chasteen ND, Lesser MP. 2006. Quenching of superoxide radicals by green fluorescent protein. Biochimica et biophysica acta 1760:1690-1695

Brocklehurst KR, Morby AP. 2000. Metal-ion tolerance in Escherichia coli: Analysis of transcriptional profiles by gene-array technology. Microbiology 146:2277-2282

Cohen I, Bitan R, Nitzan Y. 1991. The effect of zinc and cadmium ions on Escherichia coli B. Microbios 68:157-168

David G, Blondeau K, Schiltz M, Penel S, Lewit-Bentley A. 2003. YodA from Escherichia coli is a Metal-binding, Lipocalin-like Protein. Journal of Biological Chemistry 278:4372843735

Egler M, Grosse C, Grass G, Nies DH. 2005. Role of the extracytoplasmic function protein family sigma factor RpoE in metal resistance of Eschenchia coli. Journal of Bacteriology 187:2297-2307

Faber F, Egli T, Harder W. 1993. Transient repression of the synthesis of OmpF and aspartate transcarbamoylase in Escherichia coli $\mathrm{K} 12$ as a response to pollutant stress. FEMS microbiology letters 111:189-195

Ferianc P, Farewell A, Nyström T. 1998. The cadmium-stress stimulon of Escherichia coli K-12. Microbiology 144:1045-1050

Geslin C, Llanos J, Prieur D, Jeanthon C. 2001. The manganese and iron superoxide dismutases protect Escherichia coli from heavy metal toxicity. Research in Microbiology 152:901905

Giovanella P, Cabral L, Costa AP, de Oliveira Camargo FA, Gianello C, Bento FM. 2017. Metal resistance mechanisms in Gram-negative bacteria and their potential to remove $\mathrm{Hg}$ in the presence of other metals. Ecotoxicology and environmental safety 140:162-169

Han MJ, Lee SY. 2006. The Escherichia coli proteome: past, present, and future prospects. Microbiology and molecular biology reviews 70:362-439

He Y, Ma W, Li Y, Liu J, Jing W, Wang L. 2014. Expression of metallothionein of freshwater crab (Sinopotamon henanense) in Escherichia coli enhances tolerance and accumulation of zinc, copper and cadmium. Ecotoxicology 23:56-64

Helbig K, Grosse C, Nies DH. 2008. Cadmium toxicity in glutathione mutants of Escherichia coli. Journal of Bacteriology 190:5439-5454

Hossain ST, Mallick I, Mukherjee SK. 2012. Cadmium toxicity in Escherichia coli: Cell morphology, Z-ring formation and intracellular oxidative balance. Ecotoxicology and Environmental Safety 86:54-59 
587

588

589

590

591

592

593

594

595

596

597

598

599

600

601

602

603

604

605

606

607

608

609

610

611

612

613

614

615

616

617

618

619

620

621

622

623

624

625

626

627

628

629

630

Hou YM, Kim R, Kim SH. 1988. Expression of the mouse metallothionein-I gene in Escherichia coli: increased tolerance to heavy metals. Biochimica et Biophysica Acta - Gene Structure and Expression 951:230-234

Isarankura-Na-Ayudhya C, Suwanwong Y, Boonpangrak S, Kiatfuengfoo R, Prachayasittikul V. 2005. Co-expression of zinc binding motif and GFP as a cellular indicator of metal ions mobility. International journal of biological sciences 1:146-151

Isarankura-Na-Ayudhya P, Isarankura-Na-Ayudhya C, Treeratanapaiboon L, Kasikun K, Thipkeaw K, Prachayasittikul V. 2009. Proteomic profiling of Escherichia coli in response to heavy metals stress. European Journal of Scientific Research 25:679-688

Isarankura-Na-Ayudhya $\mathrm{P}$, Isarankura-Na-Ayudhya $\mathrm{C}$, Yainoy S, Thippakorn $\mathrm{C}$, Singhagamol W, Polprachum W, Roytrakul S, Prachayasittikul V. 2010. Proteomic alterations of Escherichia coli by paraquat. EXCLI Journal 9:108-118

Kashiwagi K, Miyaji A, Ikeda S, Tobe T, Sasakawa C, Igarashi K. 1992. Increase of sensitivity to aminoglycoside antibiotics by polyamine-induced protein (oligopeptide-binding protein) in Escherichia coli. Journal of bacteriology 174:4331-4337

Kershaw CJ, Brown NL, Hobman JL. 2007. Zinc dependence of zinT (yodA) mutants and binding of zinc, cadmium and mercury by ZinT. Biochemical and Biophysical Research Communications 364:66-71

Khan Z, Rehman A, Nisar MA, Zafar S, Zerr I. 2017. Biosorption behavior and proteomic analysis of Escherichia coli P4 under cadmium stress. Chemosphere 174:136-147

Khazaeli MB, Mitra RS. 1981. Cadmium-binding component in Escherichia coli during accommodation to low levels of this ion. Applied and Environmental Microbiology 41:46-50

Kille P, Stephens P, Cryer A, Kay J. 1990. The expression of a synthetic rainbow trout metallothionein gene in E. coli. Biochimica et Biophysica Acta-Gene Structure and Expression 1048:178-186

Kondo A, Kohda J, Endo Y, Shiromizu T, Kurokawa Y, Nishihara K, Yanagi H, Yura T, Fukuda H. 2000. Improvement of productivity of active horseradish peroxidase in Escherichia coli by coexpression of Dsb proteins. Journal of bioscience and bioengineering 90:600606

Laddaga RA, Silver S. 1985. Cadmium uptake in Escherichia coli K-12. Journal of bacteriology 162:1100-1105

LaRossa RA, Smulski DR, Van Dyk TK. 1995. Interaction of lead nitrate and cadmium chloride with Escherichia coli K- 12 and Salmonella typhimurium global regulatory mutants. Journal of Industrial Microbiology 14:252-258

Lausova A, Ferianc P, Polek B. 1999. The effect of different oxidative challenge on growth and stress protein induction in Escherichia coli. Biologia 54:649-660

Lim ES, Le TH, Lee SH, Kim YH, Min J. 2009. Stress responses analysis of As(III), Cd and Pb in Escherichia coli. Toxicology and Environmental Health Sciences 1:192-195

Mahnam K, Foruzandeh S, Mirakhorli N, Saffar B. 2017. Experimental and theoretical studies of cadmium ions absorption by a new reduced recombinant defensin. Journal of biomolecular structure \& dynamics 1-11

Mejare M, Ljung S, Bulow L. 1998. Selection of cadmium specific hexapeptides and their expression as OmpA fusion proteins in Escherichia coli. Protein Engineering 11:489-494 
631 Mishra Y, Chaurasia N, Rai LC. 2009. AhpC (alkyl hydroperoxide reductase) from Anabaena sp.

632

633

634

635

636

637

638

639

640

641

642

643

644

645

646

647

648

649

650

651

652

653

654

655

656

657

658

659

660

661

662

663

664

665

666

667

668

669

670

671

672

673

674

675

676
PCC 7120 protects Escherichia coli from multiple abiotic stresses. Biochemical and Biophysical Research Communications 381:606-611

Mitra RS. 1984. Protein synthesis in Escherichia coli during recovery from exposure to low levels of $\mathrm{Cd}^{2+}$. Applied and environmental microbiology 47:1012-1016

Mitra RS, Bernstein IA. 1978. Single strand breakage in DNA of Escherichia coli exposed to Cd2. Journal of Bacteriology 133:75-80

Mitra RS, Gray RH, Chin B, Bernstein IA. 1975. Molecular mechanisms of accommodation in Escherichia coli to toxic levels of $\mathrm{Cd}^{2+}$. Journal of Bacteriology 121:1180-1188

Nair PS, Robinson WE. 2001. Cadmium binding to a histidine-rich glycoprotein from marine mussel blood plasma: potentiometric titration and equilibrium speciation modeling. Environmental toxicology and chemistry 20:1596-1604

Nguyen-nhu NT, Knoops B. 2002. Alkyl hydroperoxide reductase 1 protects Saccharomyces cerevisiae against metal ion toxicity and glutathione depletion. Toxicology letters 135:219-228

Nies DH. 1992. Resistance to cadmium, cobalt, zinc, and nickel in microbes. Plasmid 27:17-28

Nies DH. 1999. Microbial heavy-metal resistance. Applied microbiology and biotechnology 51:730-750

Pacheco CC, Passos JF, Castro AR, Moradas-Ferreira P, De Marco P. 2008. Role of respiration and glutathione in cadmium-induced oxidative stress in Escherichia coli K-12. Archives of Microbiology 189:271-278

Patel J, Zhang Q, McKay RM, Vincent R, Xu Z. 2010. Genetic engineering of Caulobacter crescentus for removal of cadmium from water. Applied biochemistry and biotechnology 160:232-243

Puskárová A, Ferianc P, Kormanec J, Homerová D, Farewell A, Nyström T. 2002. Regulation of yodA encoding a novel cadmium-induced protein in Escherichia coli. Microbiology 148:3801-3811

Romeyer FM, Jacobs FA, Masson L, Hanna Z, Brousseau R. 1988. Bioaccumulation of heavy metals in Escherichia coli expressing an inducible synthetic human metallothionein gene. Journal of Biotechnology 8:207-220

Samuelson P, Wernerus H, Svedberg M, Stahl S. 2000. Staphylococcal surface display of metalbinding polyhistidyl peptides. Applied and environmental microbiology 66:1243-1248

Shapiro N, Keasling JD. 1996. The recA gene and cadmium toxicity in Escherichia coli K12. Microbios 86:23-26

Shen JJ, Qiao ZJ, Xing TJ, Zhang LP, Liang YL, Jin ZP, Yang GD, Wang R, Pei YX. 2012. Cadmium toxicity is alleviated by AtLCD and AtDCD in Escherichia coli. Journal of applied microbiology 113:1130-1138

Sousa C, Cebolla A, De Lorenzo V. 1996. Enhanced metalloadsorption of bacterial cells displaying poly-His peptides. Nature Biotechnology 14:1017-1020

Stojnev T, Harichová J, Ferianc P, Nyström T. 2007. Function of a novel cadmium-induced YodA protein in Escherichia coli. Current Microbiology 55:99-104

Tamarit J, Cabiscol E, Ros J. 1998. Identification of the major oxidatively damaged proteins in Escherichia coli cells exposed to oxidative stress. The Journal of biological chemistry 273:3027-3032

Thomas M, Benov L. 2018. The Contribution of Superoxide Radical to Cadmium Toxicity in $E$. coli. Biological trace element research 181:361-368 
677 Vallee BL, Ulmer DD. 1972. Biochemical effects of mercury, cadmium, and lead. Annual review

678 of biochemistry 41:91-128

679 Van Dyk TK, Smulski DR, Reed TR, Belkin S, Vollmer AC, LaRossa RA. 1995. Responses to

680 toxicants of an Escherichia coli strain carrying a uspA'::lux genetic fusion and an E. coli

681 strain carrying a grpE'::lux fusion are similar. Applied and Environmental Microbiology

$682 \quad 61: 4124-4127$

683 Wang G, Conover RC, Olczak AA, Alamuri P, Johnson MK, Maier RJ. 2005. Oxidative stress

684

685

686

687

688

689

690 defense mechanisms to counter iron-promoted DNA damage in Helicobacter pylori. Free radical research 39:1183-1191

Westermeier R, Scheibe B. 2008. Difference gel electrophoresis based on lys/cys tagging. Methods in molecular biology 424:73-85

Wu LF, Mandrand-Berthelot MA. 1995. A family of homologous substrate-binding proteins with a broad range of substrate specificity and dissimilar biological functions. Biochimie 77:744-750

691 


\section{Table $\mathbf{1}$ (on next page)}

Proteins of Escherichia coli TG1 host identified by mass spectrometry and peptide mass fingerprinting (PMF) analysis. 
1 Table 1. Proteins of Escherichia coli TG1 host identified by mass spectrometry and peptide 2 mass fingerprinting (PMF) analysis.

\begin{tabular}{|c|c|c|c|c|c|c|}
\hline $\begin{array}{l}\text { Spot } \\
\text { No. }\end{array}$ & Accession no. & Description & $\begin{array}{l}\text { Calculated } \\
\text { pI value }\end{array}$ & $\begin{array}{l}\text { Norminal } \\
\text { mass }\left(M_{r}\right)\end{array}$ & $\begin{array}{l}\text { Protein } \\
\text { score }\end{array}$ & $\begin{array}{c}\text { Sequence } \\
\text { coverage }(\%)\end{array}$ \\
\hline 1 & gi|485870954 & aconitate hydratase 2 & 5.22 & 91065 & 80 & 18 \\
\hline 2 & gi|486356887 & chaperone $\mathrm{ClpB}$ & 5.37 & 95712 & 76 & 31 \\
\hline 3 & gi|446438287 & molecular chaperone DnaK & 4.83 & 69096 & 115 & 46 \\
\hline 4 & gi|518680918 & heat shock protein 90 & 5.09 & 71360 & 84 & 27 \\
\hline 5 & gi 446651775 & molecular chaperone GroEL & 4.85 & 57494 & 89 & 47 \\
\hline 6 & gi|486650025 & $\begin{array}{l}\text { periplasmic oligopeptide- } \\
\text { binding protein }\end{array}$ & 6.06 & 62730 & 114 & 49 \\
\hline 7 & gi|485671395 & glycerol kinase & 5.97 & 59776 & 109 & 48 \\
\hline 8 & gi|1311039 & $\begin{array}{l}\text { Chain A, Dipeptide Binding } \\
\text { Protein }\end{array}$ & 5.75 & 57599 & 79 & 35 \\
\hline 9 & gi|485778118 & ATP synthase F1, beta subunit & 4.90 & 50341 & 125 & 41 \\
\hline 10 & gi|33383669 & isocitrate dehydrogenase & 5.33 & 43192 & 84 & 35 \\
\hline 11 & gi| $\mid 485734442$ & tryptophanase & 5.80 & 40109 & 81 & 54 \\
\hline 12 & gi|485734442 & tryptophanase & 5.80 & 40109 & 108 & 72 \\
\hline 13 & gi|445923422 & elongation factor- $\mathrm{Tu}$ & 5.07 & 41052 & 89 & 44 \\
\hline 14 & gi| 485752584 & phosphoglycerate kinase & 5.02 & 40719 & 104 & 59 \\
\hline 15 & gi|485747310 & $\begin{array}{l}\text { glycerophosphodiester } \\
\text { phosphodiesterase }\end{array}$ & 5.15 & 36482 & 79 & 51 \\
\hline 16 & gi|485696065 & fructose-bisphosphate aldolase & 5.52 & 39337 & 88 & 41 \\
\hline 17 & gi|485665932 & $\begin{array}{l}\text { glyceraldehyde-3-phosphate } \\
\text { dehydrogenase }\end{array}$ & 6.33 & 36204 & 71 & 43 \\
\hline 18 & gi|9507742 & Outer membrane protein $\mathrm{P}$ & 5.91 & 35477 & 88 & 42 \\
\hline 19 & gi|485723954 & malate dehydrogenase & 5.62 & 32532 & 72 & 48 \\
\hline 20 & gi|510898944 & $\begin{array}{l}\text { D-ribose-binding periplasmic } \\
\text { protein }\end{array}$ & 6.85 & 30949 & 72 & 50 \\
\hline 21 & gi| 486435677 & uridine phosphorylase & 5.71 & 27262 & 98 & 68 \\
\hline 22 & gi|485953066 & translation elongation factor-Ts & 5.18 & 28505 & 74 & 39 \\
\hline 23 & gi|487374764 & $\begin{array}{l}\text { purine nucleoside } \\
\text { phosphorylase }\end{array}$ & 5.42 & 26157 & 78 & 34 \\
\hline 24 & gi|485673269 & $\begin{array}{c}\text { glyceraldehyde-3-phosphate } \\
\text { dehydrogenase }\end{array}$ & 6.32 & 31252 & 74 & 36 \\
\hline 25 & gi|447012380 & $\begin{array}{l}\text { amino acid } \mathrm{ABC} \text { transporter } \\
\text { substrate-binding protein }\end{array}$ & 7.74 & 27159 & 73 & 42 \\
\hline 26 & gi|170172436 & $\begin{array}{l}\text { alkyl hydroperoxide reductase } \\
\text { C22 protein }\end{array}$ & 4.92 & 19250 & 92 & 56 \\
\hline 27 & gi|487464714 & $\begin{array}{c}\text { glucose-specific } \\
\text { phosphotransferase enzyme }\end{array}$ & 4.73 & 18198 & 87 & 43 \\
\hline 28 & gi $\mid 446006533$ & lipid hydroperoxide peroxidase & 4.75 & 17952 & 76 & 61 \\
\hline 29 & gi|485651470 & $\begin{array}{l}\text { DNA starvation/stationary } \\
\text { phase protection protein Dps }\end{array}$ & 5.72 & 18711 & 85 & 69 \\
\hline 30 & gi|486164894 & 50S ribosomal protein L9 & 6.17 & 15772 & 78 & 48 \\
\hline 31 & gi|446245719 & universal stress protein A & 5.11 & 16086 & 71 & 70 \\
\hline
\end{tabular}




\section{Table 2 (on next page)}

Changes of differentially expressed proteins of $E$. coli TG1 following exposure to cadmium. 
1 Table 2. Changes of differentially expressed proteins of E. coli TG1 following exposure to 2 cadmium.

\begin{tabular}{|c|c|c|c|c|c|}
\hline \multirow[b]{2}{*}{ Protein } & \multicolumn{5}{|c|}{ Up(+)/Down(-) regulation (fold) } \\
\hline & $\begin{array}{c}\text { TG1carrying } \\
\text { pUC19 } \\
\text { plasmid }\end{array}$ & $\begin{array}{c}\text { TG1 } \\
\text { expressing } \\
\text { GFP }\end{array}$ & $\begin{array}{c}\text { TG1 } \\
\text { expressing } \\
\text { His6GFP }\end{array}$ & $\begin{array}{c}\text { TG1 } \\
\text { expressing } \\
\text { OmpA }\end{array}$ & $\begin{array}{c}\text { TG1 } \\
\text { expressing } \\
\text { His-OmpA }\end{array}$ \\
\hline \multicolumn{6}{|l|}{ Energy metabolism } \\
\hline \multicolumn{6}{|l|}{ Glycolysis } \\
\hline $\begin{array}{c}\text { Glyceraldehyde-3-phosphate } \\
\text { dehydrogenase (1) }\end{array}$ & -2.02 & -1.84 & Absence & +2.69 & Absence \\
\hline $\begin{array}{c}\text { Glyceraldehyde-3-phosphate } \\
\text { dehydrogenase (2) }\end{array}$ & +1.75 & +1.65 & -1.06 & -2.29 & +1.63 \\
\hline \multicolumn{6}{|l|}{ Tricarboxylic acid cycle } \\
\hline Aconitase & -1.20 & No change & Absence & No change & Absence \\
\hline \multicolumn{6}{|l|}{ Glycerol uptake and lipolysis } \\
\hline Glycerol kinase & -1.60 & +1.73 & +1.92 & +1.43 & +1.33 \\
\hline \multicolumn{6}{|l|}{ Protein biosynthesis machinery } \\
\hline Translation elongation factor-Ts & +2.12 & +1.84 & +1.35 & -0.39 & +1.37 \\
\hline \multicolumn{6}{|l|}{ Transporters } \\
\hline Oligopeptide-binding protein & -1.65 & +1.37 & -1.34 & +1.22 & +1.21 \\
\hline $\begin{array}{c}\text { Amino acid } \mathrm{ABC} \text { transporter } \\
\text { substrate-binding protein }\end{array}$ & -1.42 & +1.37 & +1.29 & $\begin{array}{c}\text { No } \\
\text { detectable }\end{array}$ & +1.24 \\
\hline H+-transporting ATPase & +2.69 & -1.09 & +1.30 & -2.64 & No change \\
\hline ATP synthase F1, beta subunit & +1.32 & +1.26 & +1.08 & +1.86 & -1.44 \\
\hline \multicolumn{6}{|l|}{ Stress defense mechanism } \\
\hline MnSOD & +2.20 & +1.29 & -1.65 & No detectable & +2.08 \\
\hline Alkyl hydroperoxide reductase & -1.15 & +1.71 & -1.10 & +1.52 & -1.01 \\
\hline $\begin{array}{l}\text { DNA starvation/stationary phase } \\
\text { protection protein; Dps }\end{array}$ & -3.29 & $\begin{array}{l}\text { Low } \\
\text { amount }\end{array}$ & -1.35 & $\begin{array}{l}\text { Low } \\
\text { amount }\end{array}$ & -1.05 \\
\hline \multicolumn{6}{|l|}{ Others } \\
\hline Ribosomal protein L9 & +2.08 & +1.33 & -1.29 & +1.42 & +1.57 \\
\hline GFP & $\begin{array}{c}\text { No } \\
\text { detectable } \\
\end{array}$ & -1.45 & $\begin{array}{c}\text { No } \\
\text { detectable }\end{array}$ & $\begin{array}{c}\text { No } \\
\text { detectable } \\
\end{array}$ & $\begin{array}{c}\text { No } \\
\text { detectable }\end{array}$ \\
\hline His6GFP & $\begin{array}{c}\text { No } \\
\text { detectable }\end{array}$ & $\begin{array}{c}\text { No } \\
\text { detectable }\end{array}$ & -2.24 & $\begin{array}{c}\text { No } \\
\text { detectable }\end{array}$ & $\begin{array}{c}\text { No } \\
\text { detectable }\end{array}$ \\
\hline Disulfide isomerase I & -1.71 & $\begin{array}{c}\text { Not } \\
\text { determined }\end{array}$ & -1.85 & $\begin{array}{c}\text { Not } \\
\text { determined }\end{array}$ & -1.36 \\
\hline OmpA (1) & -1.68 & -1.26 & -1.40 & -1.35 & Absence \\
\hline OmpC precursor & -1.15 & -1.31 & -1.56 & +1.32 & +2.11 \\
\hline $\mathrm{OmpF}$ & -1.18 & Absence & Absence & No change & Absence \\
\hline
\end{tabular}




\section{Figure 1}

Expression of GFP in tested cells as deduced from UV illumination.

Non-fluorescent colonies of TG1 host (A) and TG1 carrying pUC19 (B) as well as greenish fluorescent colonies of $E$. coli expressing native GFP (C) or His6GFP (D).

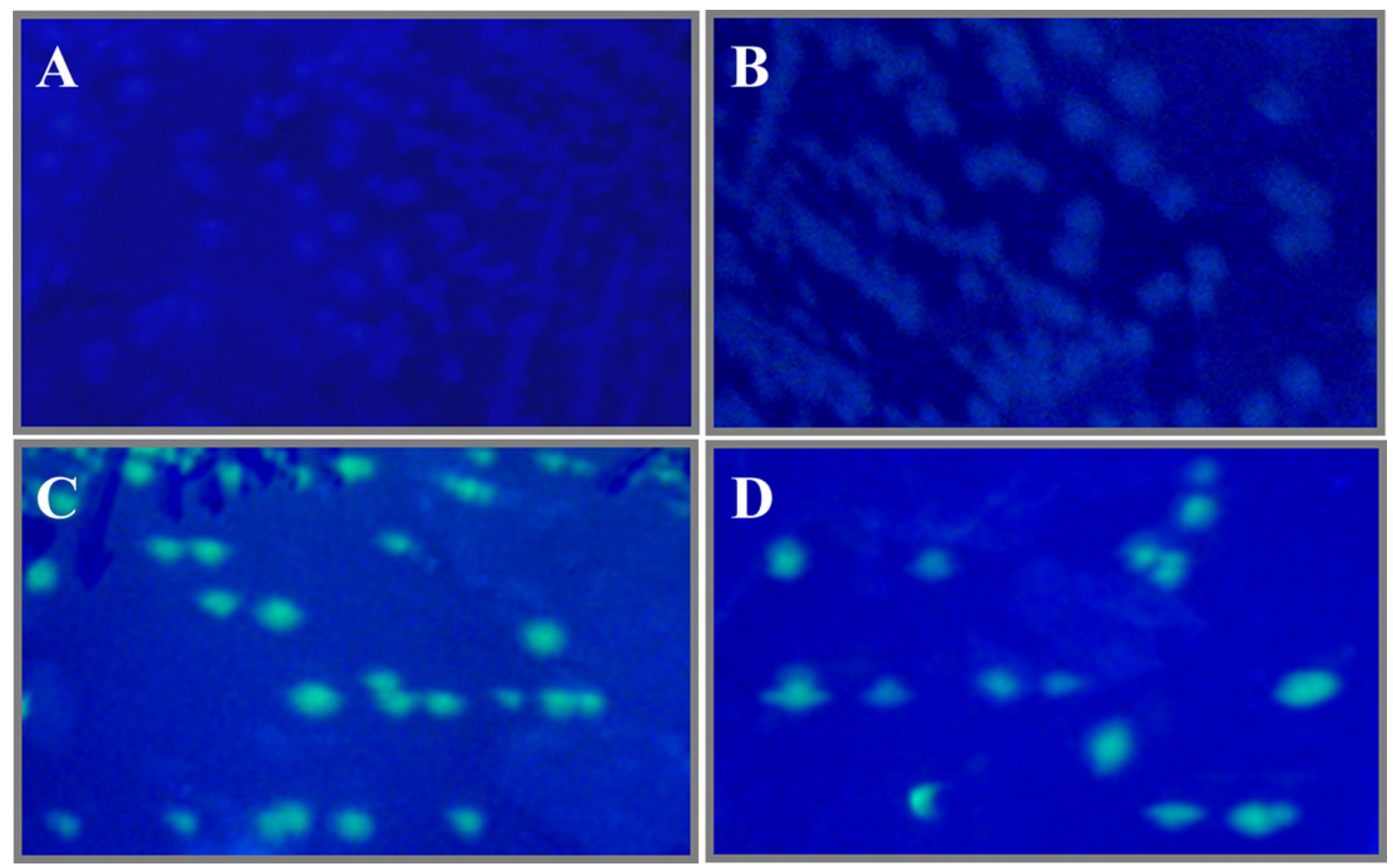




\section{Figure 2 (on next page)}

Effect of cadmium stress on E. coli expressing chimeric His6GFP, cells expressing native GFP and cells carrying control plasmid (pUC19).

Growth patterns of TG1/pUC19 (A), TG1/pGFPuv (B) and TG1/pHis6GFP (C) in the absence (opened symbol) or presence (closed symbol) of $0.2 \mathrm{mM}$ cadmium ions. 
Figure 3

Reference map representing protein profiles of $E$. coli TG1.

Numbers of protein spot represents identified proteins as presented in Table 1.

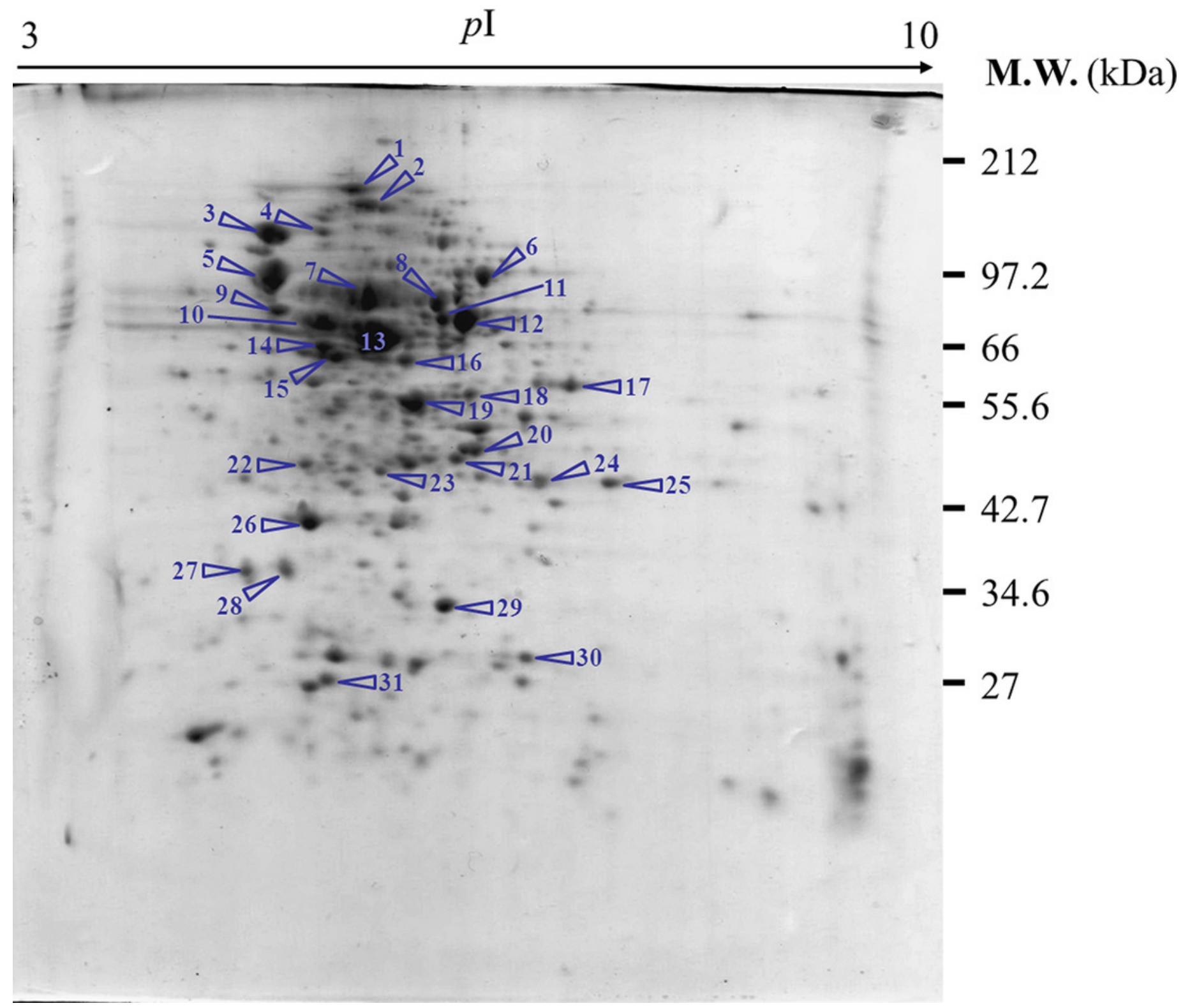


Figure 4

Protein expression profiles of $E$. coli grown in the presence of $0.2 \mathrm{mM}$ cadmium ions.

TG1/pUC19 (A), TG1/pGFPuv (B) and TG1/pHis6GFP (C). 


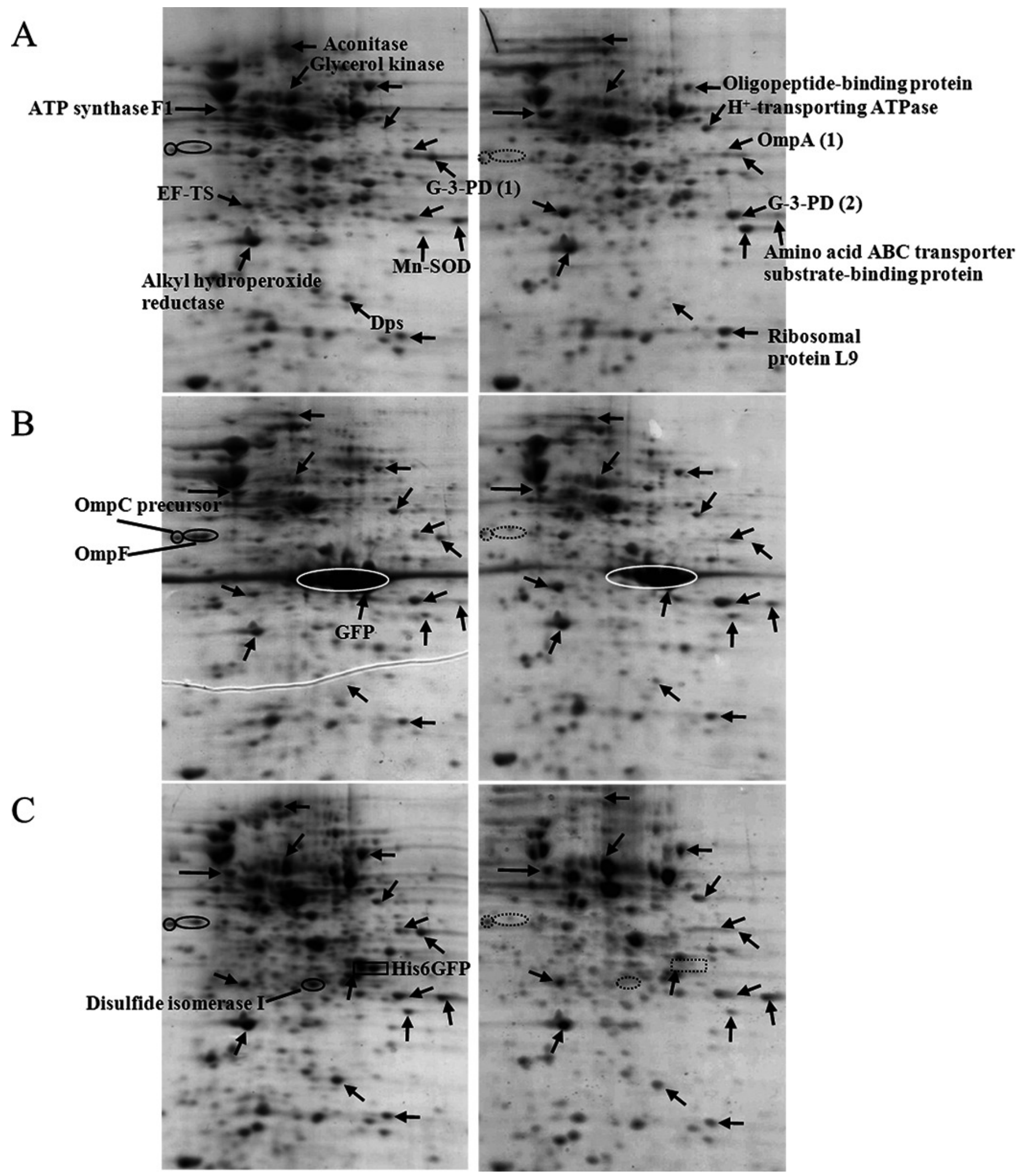


Figure 5 (on next page)

Growth patterns of $E$. coli grown in the presence of $0.2 \mathrm{mM}$ cadmium ions.

TG1/pEV208 (square) and TG1/pEVZn (diamond) in the absence (opened symbol) or presence (closed symbol) of $0.2 \mathrm{mM}$ cadmium ions. 


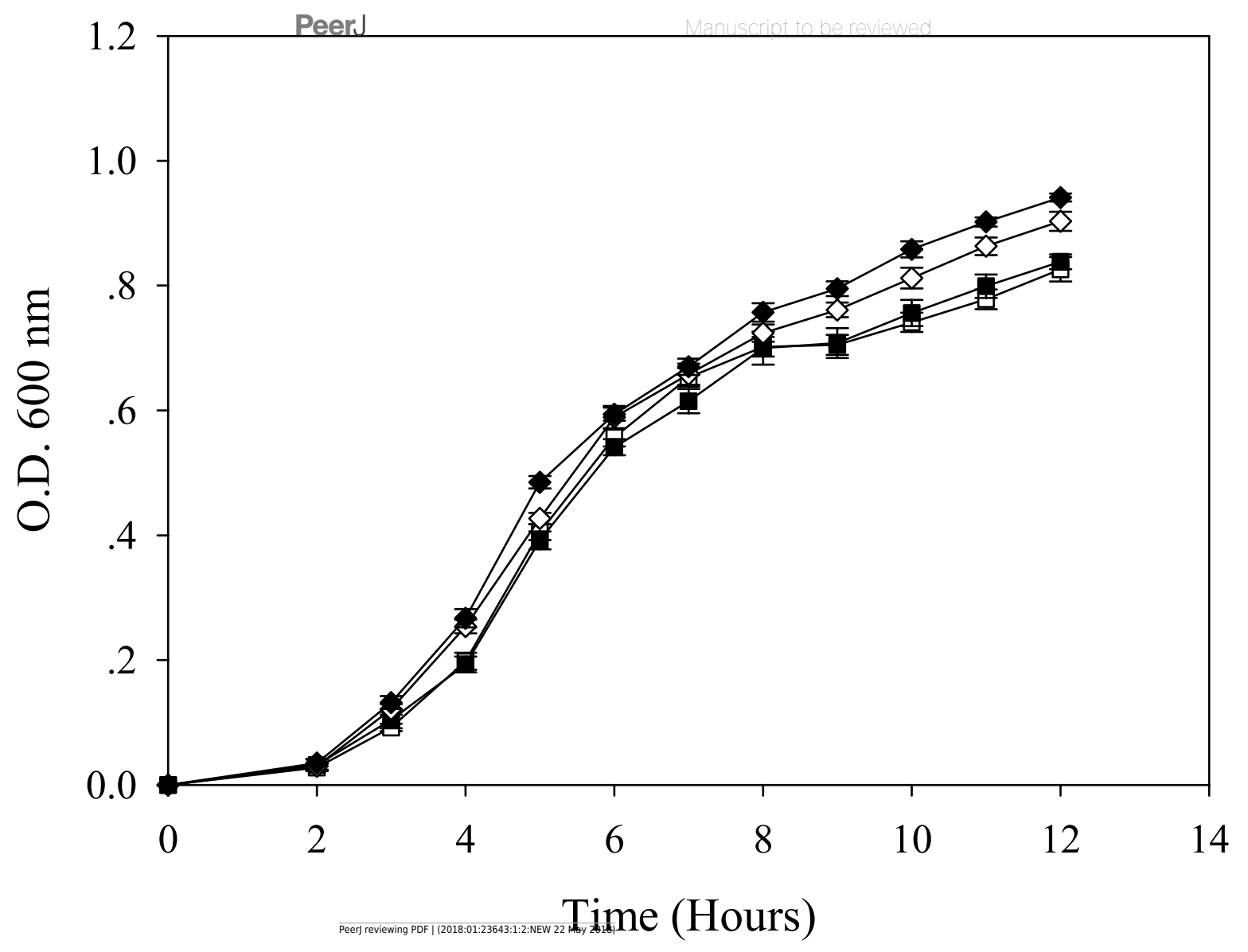




\section{Figure 6}

Protein expression profiles of $E$. coli grown in the presence of $0.2 \mathrm{mM}$ cadmium ions.

TG1/pEV208 (A) and TG1/pEVZn (B).

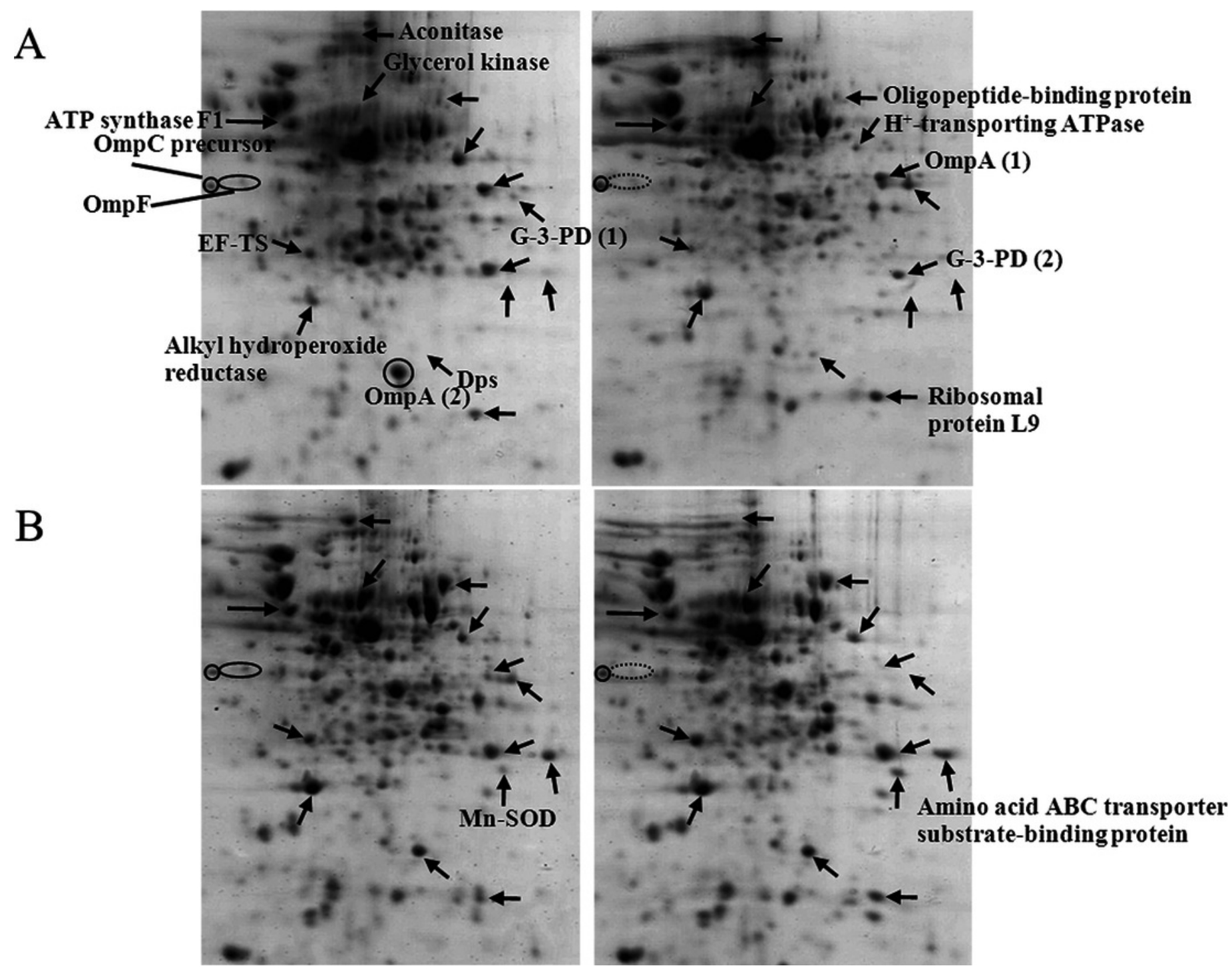




\section{Figure 7}

Quantitative proteomic analysis of proteins via 2D-DIGE.

Two different samples were individually labeled with two kinds of fluorescent dyes (Cy3 and Cy5) and co-separated in one gel (A). An internal standard, derived from a mixture of all samples pooled together and labeled as $\mathrm{Cy} 2$, was created to facilitate the normalization of each spot among all gels. Protein spots with changes in abundance ratio of 1.5 fold and $P$ values $<0.05$ (Student's $t$-test) were identified and compared between the gels (B). 


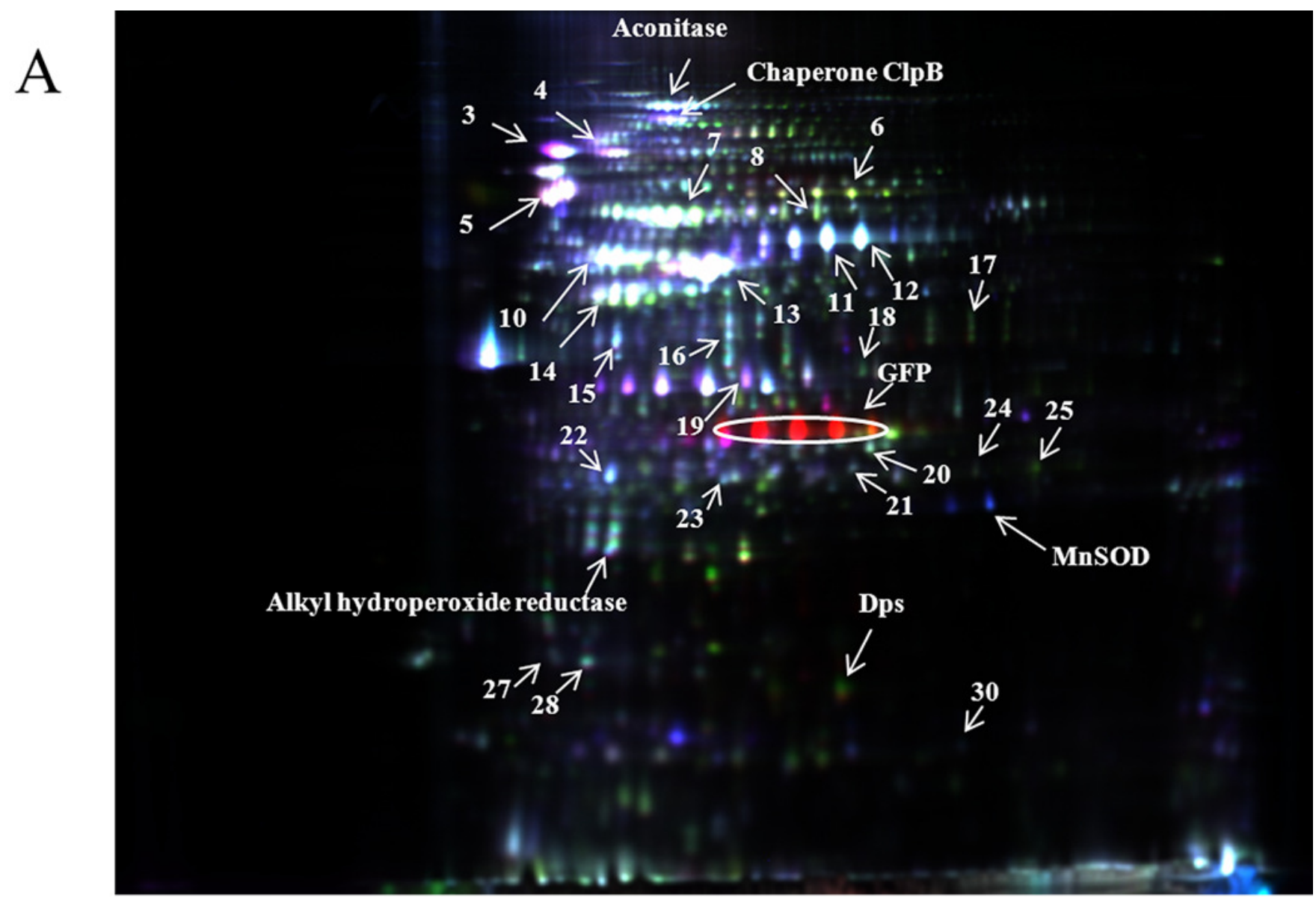

Alkyl hydroperoxide reductase
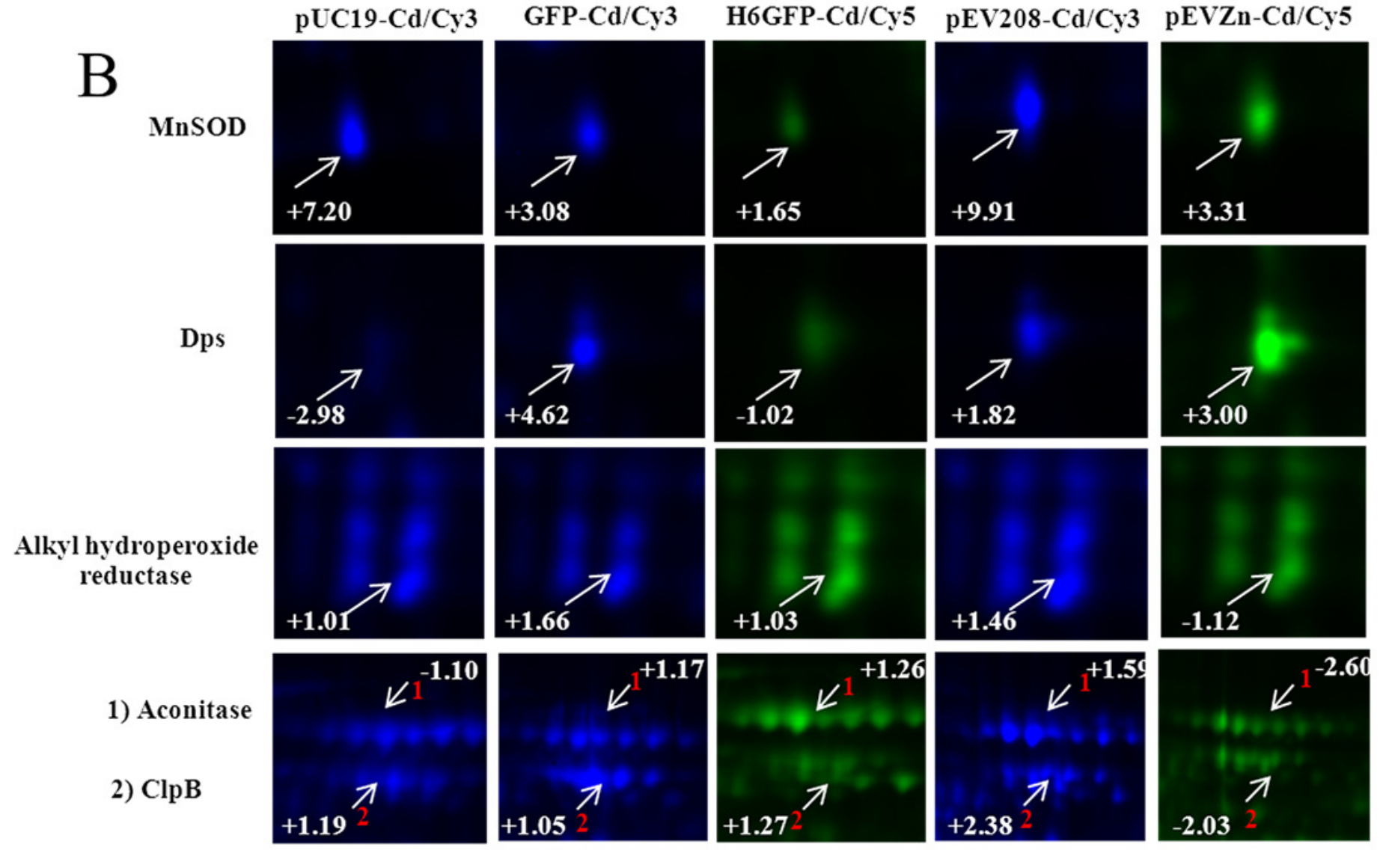
Figure 8

\section{Relationship between genes encoding proteins of $E$. coli involved in responses to cadmium stress as identified by the STRING software.}

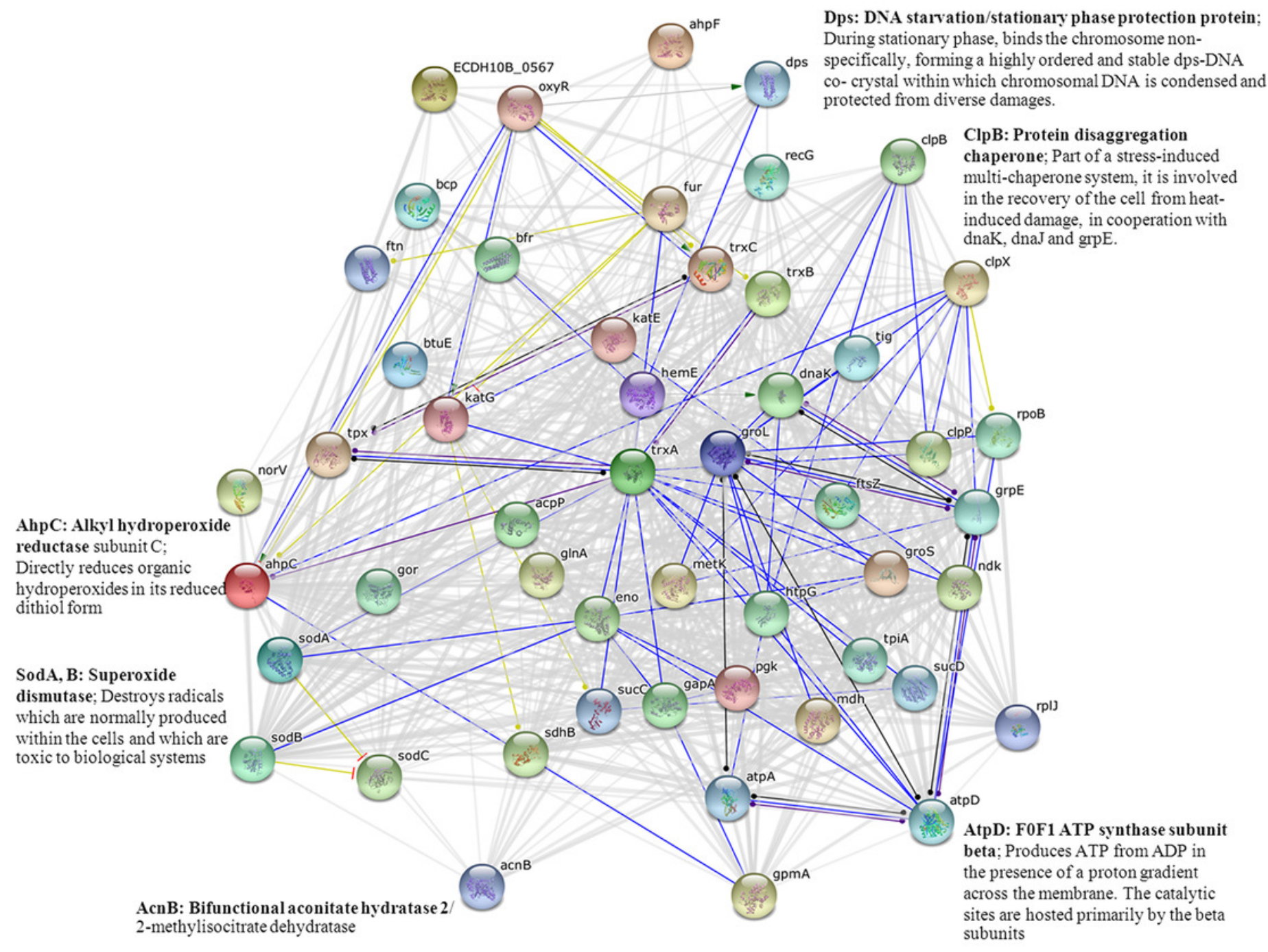




\section{Figure 9 (on next page)}

A proposed molecular mechanism of cellular responses and adaptation in the presence of toxic cadmium ions.

Responses against cadmium of $E$. coli cells expressing cytoplasmic His6GFP (A) and cells expressing His-OmpA (B). 
